\title{
TOWARD THE ASSESSMENT OF MECHANICAL ROBUSTNESS \\ OF CERAMIC MULTILAYER CAPACITORS (MLCs)
}

\author{
A. A. Wereszczak, ${ }^{1,2}$ K. Breder, ${ }^{1}$ L. Riester, ${ }^{3}$ T. P. Kirkland, ${ }^{3}$ and R. J. Bridge ${ }^{3,4}$ \\ Mechanical Characterization and Analysis Group \\ Oak Ridge National Laboratory \\ Oak Ridge, TN 37831-6069 \\ i \\ Prepared for the \\ Advanced Automotive Propulsion Materials Program \\ Office of Transportation Technologies \\ Assistant Secretary for Energy Efficiency and Renewable Energy \\ U.S. Department of Energy \\ EE0701000

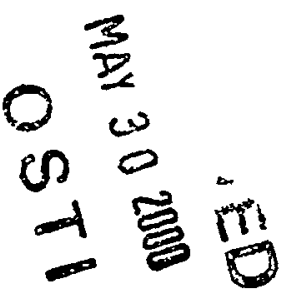

Prepared by the

OAK RIDGE NATIONAL LABORATORY

Oak Ridge, Tennessee 37831-6285

managed by

LOCKHEED MARTIN ENERGY RESEARCH CORP.

for the

U.S. DEPARTMENT OF ENERGY

under contract DE-AC05-96OR22464

1 Principal investigator.

2 Author for correspondence (wereszczakaa@ornl.gov).

3 Contributing investigator.

4 A student at the University of Connecticut, Storrs, CT, at the time that this work was conducted. 


\section{DISCLAIMER}

This report was prepared as an account of work sponsored by an agency of the United States Government. Neither the United States Government nor any agency thereof, nor any of their employees, make any warranty, express or implied, or assumes any legal liability or responsibility for the accuracy, completeness, or usefulness of any information, apparatus, product, or process disclosed, or represents that its use would not infringe privately owned rights. Reference herein to any specific commercial product, process, or service by trade name, trademark, manufacturer, or otherwise does not necessarily constitute or imply its endorsement, recommendation, or favoring by the United States Government or any agency thereof. The views and opinions of authors expressed herein do not necessarily state or reflect those of the United States Government or any agency thereof. 


\section{DISCLAIMER}

Portions of this document may be illegible in electronic image products. Images are produced from the best available original document. 


\section{Executive Summary}

The present study consisted of two efforts: the measurement of several mechanical properties of dielectric ceramics in MLCs and the consideration of what effects other parameters have on MLC mechanical reliability or "robustness." If MLC mechanical reliability is a limiting factor to long-term electronic function, then it is clearly advantageous to use a MLC with maximum mechanical robustness. The results and additional mechanical considerations are described from the perspective of structural ceramic design and interpreted in a manner that a MLC manufacturer or end-user may use to improve MLC mechanical reliability. The trends in the measured properties and other parameters in toto portray the potential MLC mechanical robustness.

The measurement of mechanical properties of the dielectric ceramics in MLCs comprised the majority of this study. The Young's modulus, hardness, fracture toughness, and potential strength distributions (calculated from a measured hypothetical flaw-size distribution) of the dielectric ceramics in three equivalent (X7R $08050.1 \mu \mathrm{F}$ ) MLCs were measured in-situ. The three MLCs were kept anonymous and designated as MLC-A, MLC-B, and MLC-C. From a perspective of a structural ceramic designer, the authors conclude that if the three MLC sets were to be subjected to an equal service stress state that the dielectric ceramic in the MLC-C would mechanically perform the best, followed in turn by the dielectric ceramic in the MLC-A and then that in the MLC-B (all other things being equal). This conclusion is based on the dielectric ceramic in MLC-C having the highest characteristic strength (through the consideration of secondary phase inclusions) and fracture toughness. The approaches of the in-situ fracture toughness and strength determinations involving dielectrics in MLCs were unique.

- Young's modulus, hardness, and fracture toughness of the dielectric ceramics in the MLCs were determined using a mechanical properties microprobe (MPM). These properties were measured in-situ after careful specimen preparation and metallography. The reporting of such in-situ measurements using the MPM was not located in the literature, so the authors suspect that this may be their first-time presentation.

- The potential strength distributions of the dielectric ceramic materials were calculated from a measured flaw-size distribution. Both pores and secondary phase "inclusions" were considered in the present study as possible strength-limiting flaws in these dielectric ceramics (similar flaws are common strength-limiters in structural ceramics). Their size distributions were quantified using a combination of scanning electron microscope imaging and subsequent digital image analysis. The flaw size distribution and the 
measured fracture toughness of each dielectric ceramic were then combined using a Griffith criterion and the measured in-situ fracture toughnesses to calculate a corresponding strength distribution. The resulting strength distributions of the MLCs were then compared.

Other factors, although not quantified, can also affect mechanical performance and should be considered in the optimization of mechanical robustness (or in the design of the MLC). Parameters such as electrode centering, dielectric ceramic Weibull modulus, cover layer and margin thicknesses, residual stress, stress-free temperature, adhesion strength of adjoining laminates in MLC cover layers, thickness of laminates comprising the cover layer, glass frit effects, and thermal shock susceptibility can all affect MLC mechanical robustness, and their roles in mechanical reliability were qualitatively presented. It is advantageous to promote electrode centering, use a dielectric ceramic with a maximum Weibull modulus, maximize cover layer and margin thicknesses, minimize residual tensile stresses and the stress-free temperature, maximize adhesion strength of cover layer laminates (or maximize cover layer thickness if adhesion strength is not maximized), and minimize glass frit penetration at the end of the termination metal. These trends will all act to maximize mechanical robustness and promote longer-term electronic function of MLCs.

The authors believe that appropriate design of a MLC, in which service- or manufacturing-induced tensile stresses are minimized, will have more of an impact on improved MLC mechanical robustness than any improvement in mechanical properties of barium titanate $\left(\mathrm{BaTiO}_{3}\right)$ ceramics. Barium titanate ceramics were never intended to be structural materials, so a drastic improvement in their mechanical properties is unlikely. Although the fracture toughnesses and strengths of structural ceramics have doubled or even tripled over the years as their engineering has matured, it is doubtful that $\mathrm{BaTiO}_{3}$ ceramics will enjoy the same development. Appropriate or improved design to limit service tensile stresses will likely have more of an effect in the improvement of MLC mechanical robustness than tinkering with $\mathrm{BaTiO}_{3}$ to make it twice as tough or strong. Doubling the strength and fracture toughness of $\mathrm{BaTiO}_{3}$ ceramics would be beneficial; however, designing MLCs so that imposed tensile stresses are halved would result in the same final mechanical robustness state, and it would be much less of an engineering endeavor and therefore more plausible. 


\section{TABLE OF CONTENTS}

Page

EXECUTIVE SUMMARY

LIST OF FIGURES ........................................................................ vi

LIST OF TABLES......................................................................... viii

1. INTRODUCTION

2. APPROACH

3. MECHANICAL CHARACTERIZATION TESTS OF DIELECTRIC CERAMICS......... 4

3.1 Preparation and Geometrical Characterization of MLCs ................................. 4

3.2 In-Situ Mechanical Property Analyses of Dielectric Ceramics............................ 6

3.2.1 Young's Modulus, Hardness, and Fracture Toughness ...................... 9

3:2.2 Calculation of Strength Distribution........................................... 12

4. RESULTS AND DISCUSSION ............................................................ 15

4.1 Ceramic "Window of Design"............................................................ 15

4.2 Geometrical Issues \& Board Flexure ..................................................... 15

4.3 Mechanical Properties: Seek Maximum Strength and Toughness of the Dielectric.... 20

4.3.1 Young's Modulus and Hardness ................................................ 20

4.3.2Fracture Toughness ....................................................... 22

4.3.3 Strength Distributions.......................................................... 24

4.4 Is "Classical" Ceramic Design Applicable?................................................ 28

4.4.1 Weibull Distribution........................................................... 29

4.4.2Strength-Size Scaling ....................................................... 29

4.5 Additional Factors Affecting MLC Mechanical Robustness............................ 32

4.5.1 Residual Stress and the "Stress-Free" Temperature.......................... 32

4.5.2Knit Lines and Laminate Adhesion Strength.................................. 33

4.5.3 Glass Frit Effects at the Termination Metal.................................... 34

4.5.4 Thermal Shock .............................................................. 36

5. SUMMARY

6. REFERENCES

ACKNOWLEDGMENTS ............................................................. 41 


\section{LIST OF FIGURES}

Figure

10805 and 1206 MLCs. 0805 MLCs were mechanically characterized in the present study.................................................................. 2

2 High-voltage MLCs used in power electronic devices.......................... 2

3 A representative multilayer capacitor and its internal orthogonal crosssections...................................................................... 4

4 Measured dimensions of multilayer capacitors. .................................. 5

5 The dimensions of opposite cover layers, margins, and end margins were compared.

6 Components of the mechanical properties microprobe. The metallographically prepared specimen is mounted on top of the $X$ \& $Y$ stage.

7 Micromechanical testing was performed in the cover layer of the MLCs....

8 Example of indent pattern in MLC cover layer (a). An enlargement of the box in (a) shows the Vickers indent and the produced cracks (b) whose lengths were used in the determination of fracture toughness.

9 The size distribution of two potential strength-limiting flaw types were measured: pores and secondary phase "inclusions.".

10 Ceramic components are more mechanically robust if they are designed to be subjected to compressive stresses. The design window is asymmetric because ceramics are able to withstand higher compressive stresses than tensile stresses.

11 Schematic of a surface-mounted MLC on a flexed board (top). The board's curvature transfers a tensile force through the solder and ultimately to the MLC (bottom). This results in a relatively high shear (and tensile) stress near the bottom of the MLC.

12 The geometry of the MLC's cover layer, margins, and end margins can affect the tensile stress in a surface-mounted MLC that is subjected to board flexure.

13 The fracture toughnesses of the dielectrics in the three MLCs were different.

14 Higher dielectric fracture toughness will result in better mechanical robustness. 
15 Predicted strength distribution if (a) pores and (b) secondary phase inclusions were the strength-limiting flaw.

16 Higher dielectric tensile strength will result in better mechanical robustness.

17 A larger tensile-stress window of design exists for ceramics with a higher Weibull modulus.

18 A larger Weibull modulus is also advantageous because strength-sizescaling is not as severe as that for a ceramic with a relatively low Weibull modulus (a). An example of this size-scaling is shown in (b) for the tensile strength of a ceramic material.

19 A relatively high tensile residual stress is more detrimental to mechanical robustness.

20 Knit lines can be a source of crack initiation if bonding or adhesion of adjacent tapes is insufficient and the cover layers are subjected to sufficiently high tensile or shear stresses.

21 The depth of penetration of the glass frit at the end of the termination metal can affect mechanical robustness. A large depth in the cover layer can be problematic if the MLC's cover layer is subjected to tensile stress (like that for the case during board flexure).

22 Heating the exterior of a MLC causes the surface to be subjected to compressive stresses while the near-surface-interior is subjected to tensile stresses. This is due to thermal expansion mismatches between the termination metal and the dielectric ceramic. 


\section{LIST OF TABLES}

Table

Page

1 Dimensions of multilayer capacitors and their dielectrics and electrodes corresponding to Fig. 4.

2 Dimensions of dielectric cover layers and margins.................................. 17

3 Electrode and dielectric layer information............................................ 18

4 Measured mechanical properties of dielectric ceramics............................. 24

5 Values of Weibull parameters for the calculated strength distributions........... 27 


\section{INTRODUCTION}

Ceramic multilayer capacitors (MLCs) are complicated structures consisting of several different materials. If the mechanical reliability of the ceramic constituents in the MLC limits its electric service function or reliability, then there is merit in understanding and predicting their mechanical performance. Understanding the mechanical reliability or "robustness"1 of ceramic MLCs is complex because many parameters can affect it. However, these parameters fall into two categories: material parameters that describe the dielectric ceramic's mechanical properties and design parameters that can dictate what (thermo)mechanical stresses are imposed on the MLC during its service or manufacture.

The authors have experience in the mechanical (including micromechanical and thermomechanical) characterization and analyses of structural ceramics and the probabilistic design of ceramic components. Interest existed to see if those experiences could be extended and applied to the mechanical characterization and analyses of an electronic ceramic device that is subjected to (thermo)mechanical stresses: a multilayer capacitor. This report describes those efforts (both the unique in-situ measurement of dielectric ceramic mechanical properties and the survey of MLC design) and discusses MLC mechanical reliability or robustness from the perspective of structural ceramists. The capacitor size examined is illustrated in the top of Fig. 1; however, techniques described in this report are amenable for use with the larger and high-voltage capacitors that are candidates for use in automotive power electronic devices and shown in Fig. 2. Freiman and Pohanka [1] published an excellent review of similar testing to what is presently described; however, the further-miniaturization of MLCs over the 10 years since that review has resulted in MLCs and dielectric ceramics that are much different and whose characterization requires refined testing procedures. The results from the presently described studies thusly provide engineering data and allow property comparison of dielectric ceramics for contemporary MLCs.

1 Mechanical robustness" is a qualitatively used term that is descriptive of the potential service reliability. 


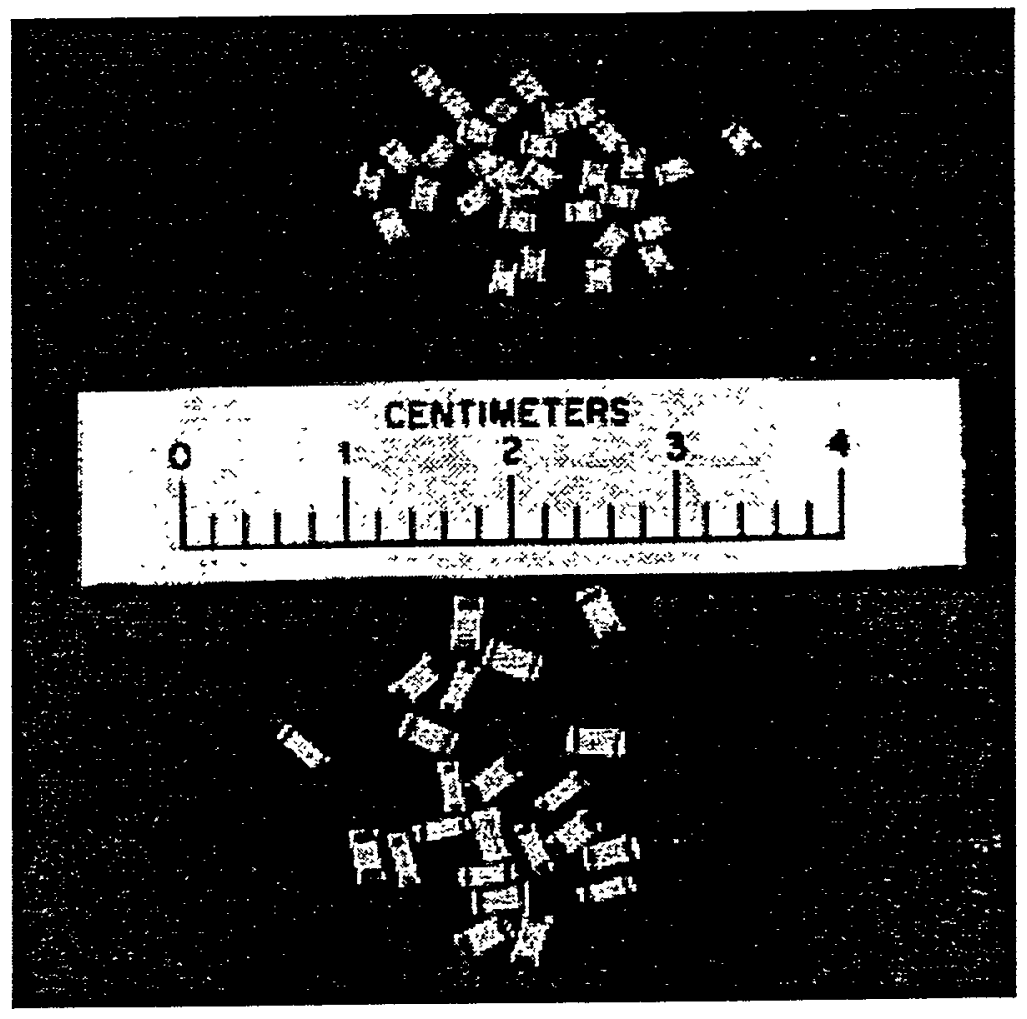

Figure 1. 0805 (top) and 1206 (bottom) MLCs. 0805 MLCs were mechanically characterized in the present study.

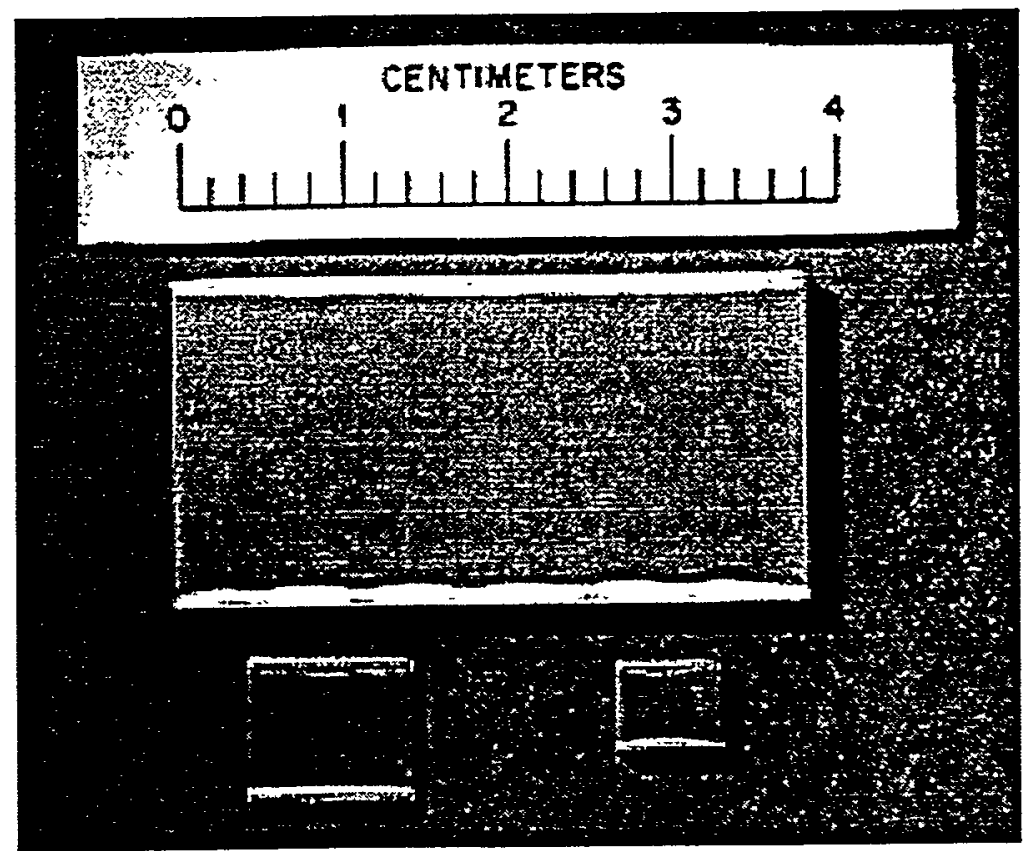

Figure 2. High-voltage MLCs used in power electronic devices. 


\section{APPROACH}

Equivalent MLCs (X7R, 0805, $0.1 \mu \mathrm{F}$ ) manufactured by three different suppliers were mechanically characterized. Their analyses and results served as the vehicle for this study. Each MLC's manufacturer was kept anonymous (designated here as MLC-A, MLC-B, and MLC-C). The results from our testing show that the dielectric ceramics in MLCs can possess subtle or significant differences even though their MLC capacitance ratings are equivalent. Based on those results and our backgrounds in structural ceramics, we then analyze which MLC is the most mechanically robust based on that testing and analysis.

Mechanical properties of the dielectric ceramics (all barium titanate, $\mathrm{BaTiO}_{3}$, based) were analyzed and their results are presented. Micromechanical properties (Young's modulus and hardness) of the dielectric ceramic were measured and compared. Additionally, the fracture toughness and strength distribution of the dielectric ceramic material in each MLC was measured and compared. The techniques that were used for these tests are described.

Design considerations were also examined and their discussions comprise the last portion of this report. Geometric issues were explored by measuring the electrode and dielectric ceramic layout within the MLCs and comparing them. Other issues including (but not limited to) residual stress, knit lines, glass frit effects, and thermal shock susceptibility are also examined. 


\section{MECHANICAL CHARACTERIZATION TESTS OF DIELECTRIC CERAMICS}

\subsection{Preparation and Geometrical Characterization of MLCs}

The examined MLCs possessed an orthotropic symmetry, so several (from each of the three manufacturers) were sectioned in half along each of the three orthogonal planes to completely reveal their internal electrode/dielectric geometry (shown in Fig. 3). A fine surface finish was a prerequisite for the planned micromechanical testing. To achieve this, the MLCs were sectioned, then set in metallographer's mounting epoxy and diamond-paste polished to a $0.25 \mu \mathrm{m}$ finish.
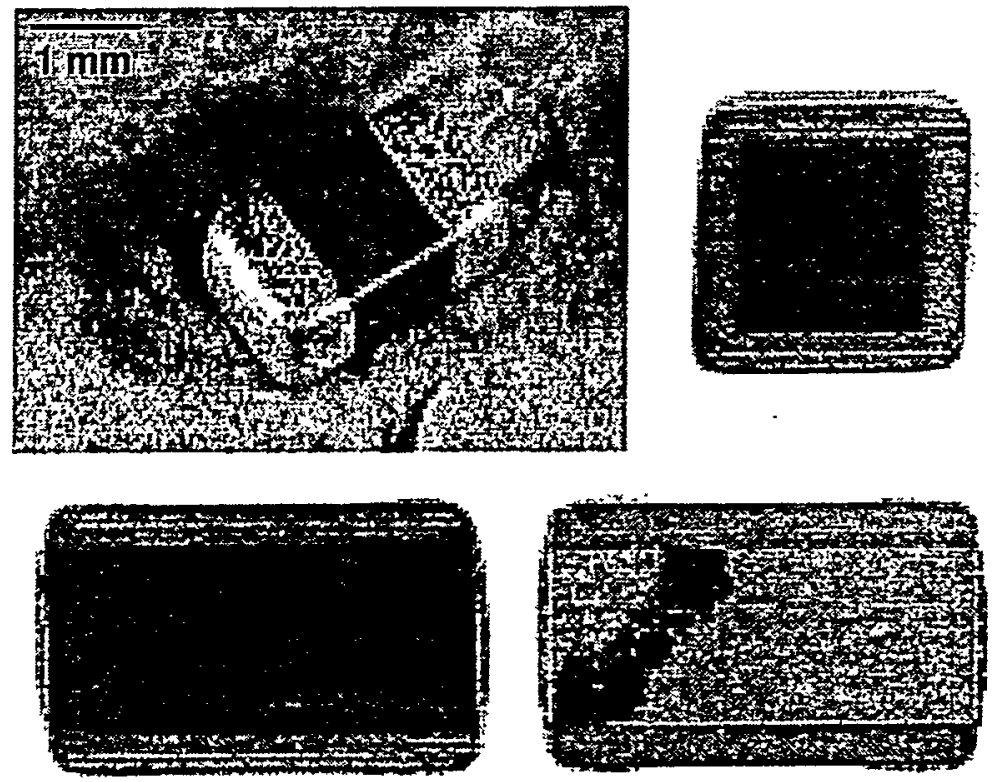

Figure 3. A representative multilayer capacitor and its internal orthogonal cross-sections.

The dimensions of the MLCs, their electrodes, and their dielectrics were measured with an optical comparator (OC). ${ }^{2}$ The OC could resolve $1 \mu \mathrm{m}$; however, the repeatability of measurement was approximately $2-3 \mu \mathrm{m}$. The dimensions that were measured are shown in Fig. 4 . All the appropriate dimensions were evident in the combination of any two of the three orthogonal planes in the MLCs. Several MLCs from each of the three sets were examined and were found to have

2 Dimensions of MLCs in each set were quite similar, so shown dimensions are from one MLC from each set. It is assumed in this analysis that the mechanical properties of the dielectric ceramic in each set's tested MLC are the same in other MLCs in the same set. 
equivalent geometries; consequently, the shown measured dimensions are from a representative MLC from each set.

This information was used to qualitatively compare the geometric nature of the electrodes and dielectrics within the MLCs. The dimensions shown in Fig. 4 were used to compare the opposite cover layer, margin, and end margin thicknesses in each of the MLC sets. The illustration of each of these is shown in Fig. 5.

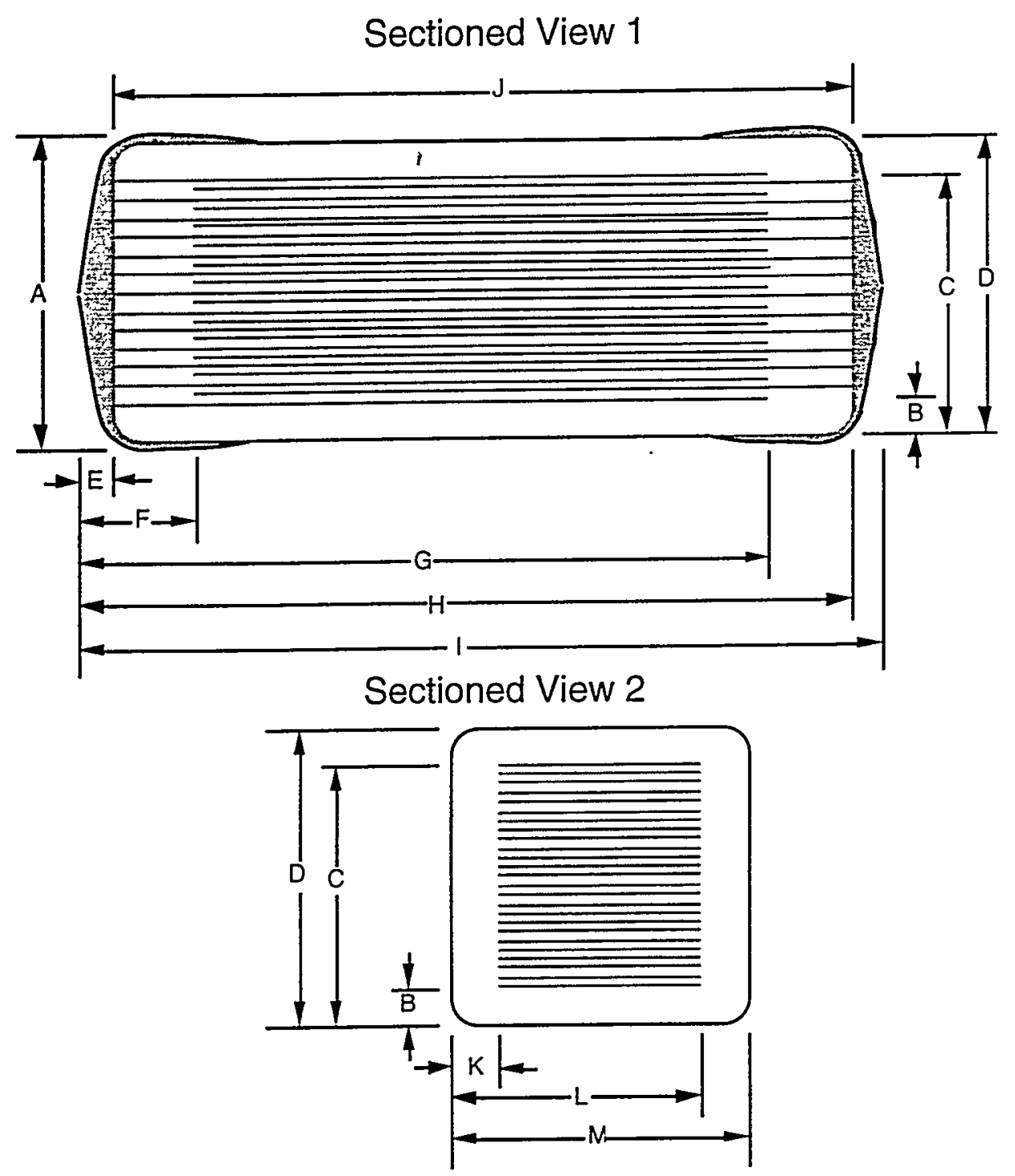

Note: These two sections are orthogonal

Figure 4. Measured dimensions of multilayer capacitors. 


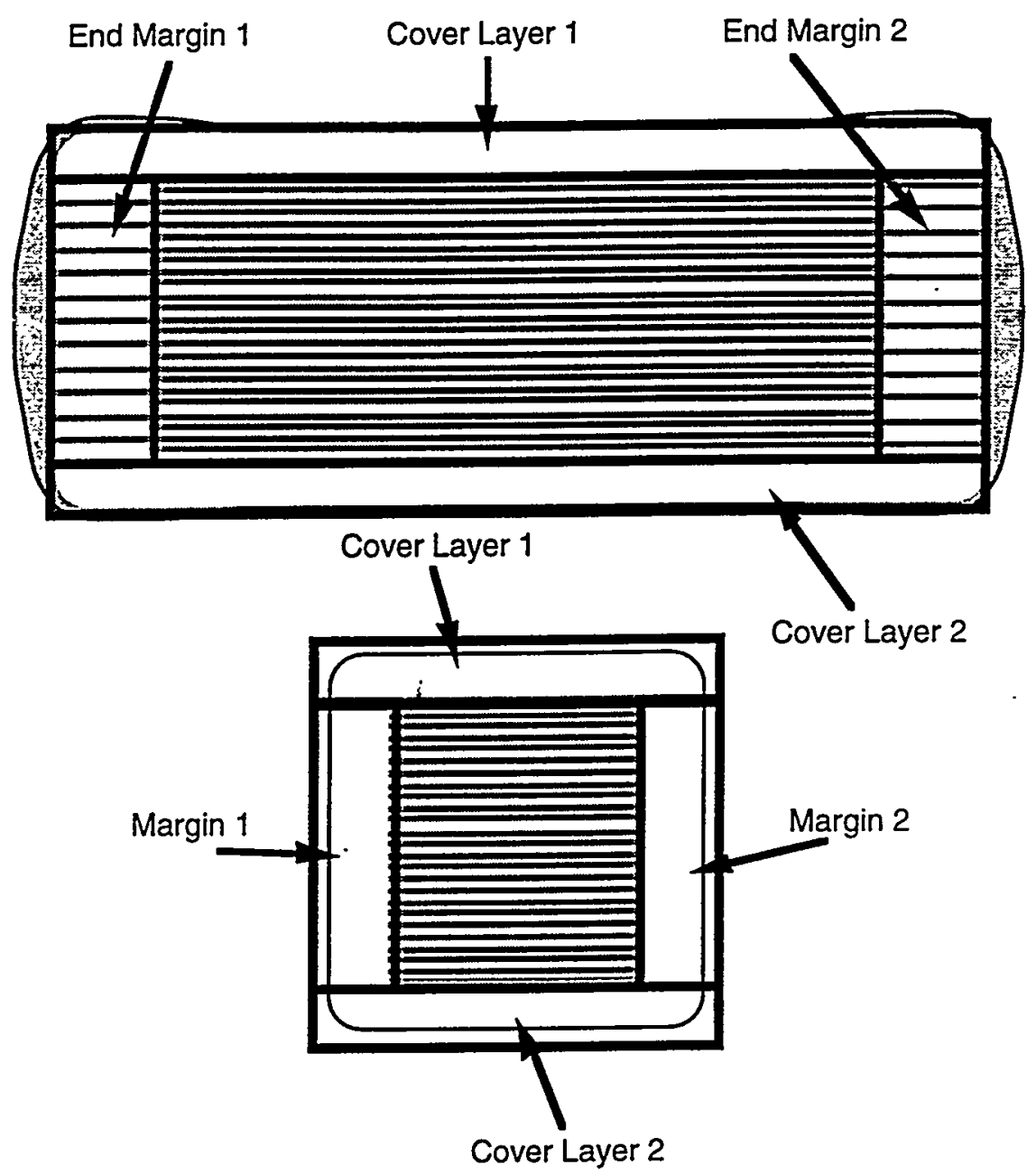

Figure 5. The dimensions of opposite cover layers, margins, and end margins were compared.

\subsection{In-Situ Mechanical Property Analyses of Dielectric Ceramics}

A mechanical properties microprobe (MPM) ${ }^{3}$ was used in the measurement of the Young's modulus $(\mathrm{E})$, hardness $(\mathrm{H})$, and for the determination of fracture toughness $\left(\mathrm{K}_{\mathrm{lc}}\right)$ of the dielectric ceramic in each of the three MLCs. The MPM is an automated instrument that consists of four primary components that are shown in Fig. 6.: an indenter whose vertical displacement (nanometer resolution) and applied load (microgram resolution) are controllable, an optical microscope $(\mathrm{OM})$ with several objective lenses, a precision $\mathrm{X} \& \mathrm{Y}$ stage that translates the metallographically prepared specimen between the $O M$ and the indenter, and a computer that controls the OM's lens turret (hence, its magnification), stage movement, and indenter load and

3 Nanoindenter II, Nano Instruments, Oak Ridge, TN. 
displacement. A diamond Berkovich indenter was used for the $\mathrm{E}$ and $\mathrm{H}$ measurements while a diamond Vickers indenter was used for the $\mathrm{K}_{\mathrm{lc}}$ measurements. The computer also collects data of the indenter's displacement and load, and is also interfaced with a TV-monitor and camera that show the microscope's field of view and allow inspection of each indent.

The MPM (not including the computer) is housed inside an insulated cabinet that minimizes its susceptibility to laboratory room temperature fluctuations and vibrations (problematic when controlling displacements at the nanometer level). The MPM is remotely operated from the computer that is outside the insulated cabinet to further minimize the introduction of thermal instabilities.

Performing the indentation testing is automated and many tests may be set up at once. After the metallographically prepared specimen mount is installed on the $X$ \& Y stage, its surface is observed with the optical microscope. The locations of interest (X and $\mathrm{Y}$ Cartesian coordinates) for indentation are then identified by the operator. An array pattern of indents along with a load waveform is programmed into the computer's software. The test is initiated and the $X \& Y$ stage moves the specimen to the indenter. For each programmed indent, the software controls the indenter's loading and continuously measures its displacement. Upon completion of the test sequence, the stage moves the specimen to the $\mathrm{OM}$ for visual inspection of the indent and the verification of each indent's position.

For the present testing, a cover layer in each MLC was chosen to be subjected to indentation. A schematic of the MLC cross-section is shown in Fig. 7 depicting the cover layer region where the micromechanical characterization was performed. Crack growth during fracture toughness testing can be affected by residual stresses; consequently, the shown cover layer region was deemed to be at a location (i.e., as far away from the termination metal as allowed) where their effects were at a minimum.

Additionally, the plastic deformation zone created in the volume of material immediately under the indent has a finite size. The cover layer region had a relatively large volume and each indent's plastic zone in this region was not restricted by edges which provided another motivation to apply indents in this location. The dielectric layers between electrodes were quite thin, so their indentation was not performed owing to concerns that edge effects would result in misleading values of $\mathrm{E}, \mathrm{H}$, and $\mathrm{K}_{\mathrm{lc}}$. 


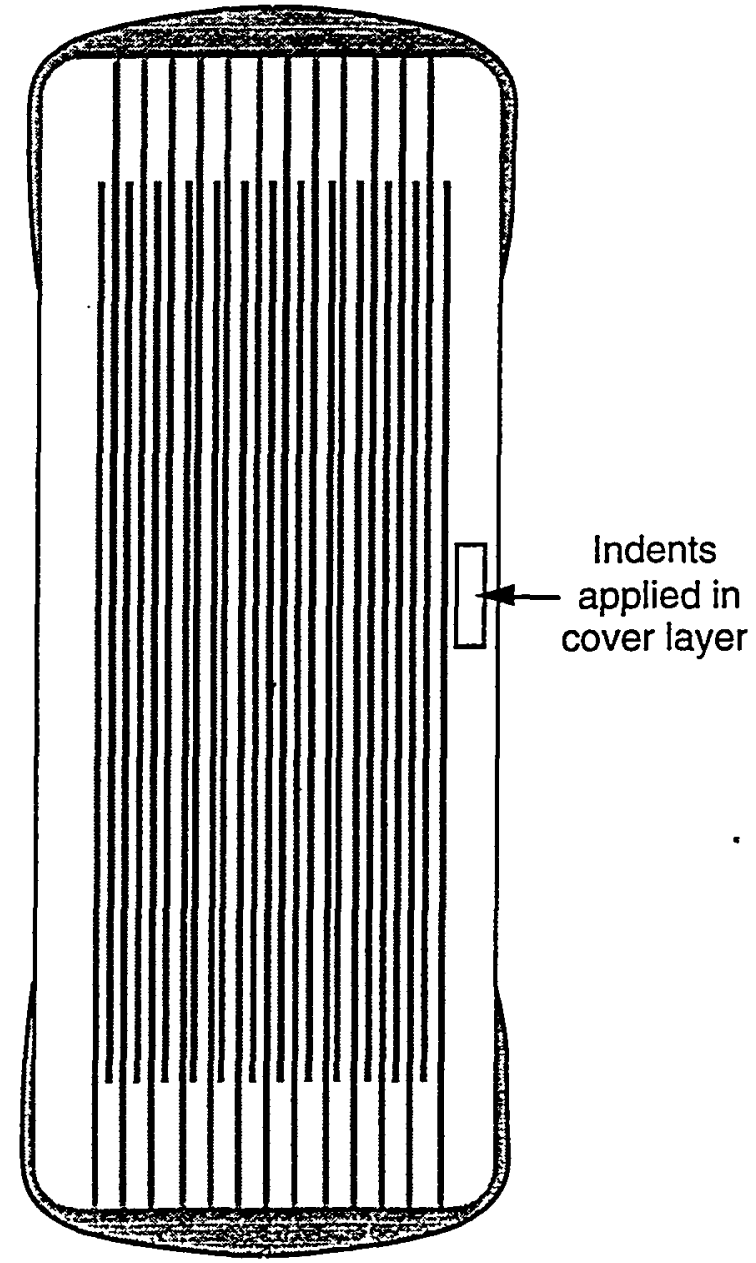

Figure 7. Micromechanical testing was performed in the cover layer of the MLCs.

\subsubsection{Young's Modulus, Hardness, and Fracture Toughness}

Relatively low loads applied with a Berkovich indenter were used for the $\mathrm{E}$ and $\mathrm{H}$ determinations (no cracks produced), while higher loads using a Vickers indenter were applied for the $\mathrm{K}_{\mathrm{lc}}$ determinations (cracks purposely produced). The load/displacement history during indentation provided data which were interpreted with the aid of an appropriate model [2] to calculate $\mathrm{E}$ and $\mathrm{H}$ of the material. Forty indents were applied in the dielectric ceramic in each MLC's cover layer, and the corresponding average $\mathrm{E}$ and $\mathrm{H}$ were calculated for each of them. 
Higher loads were applied with the Vickers indenter to produce cracks which emanated from the corners of the indent, and these cracks were used to determine $\mathrm{K}_{\mathrm{Ic}}$. The polished metallographical mounts were carbon-coated to improve conductivity of the sample. The indent-generated cracks were imaged at approximately 7000 and $10000 \mathrm{x}$ with a scanning electron microscope (SEM) to measure their lengths. An image of an indent and its generated cracks are shown in Fig 8(a)-(b). The crack length ( $\mathrm{c}$ in Fig. 8(b)), its corresponding applied indent load (P), and the measured $\mathrm{E}$ and $\mathrm{H}$ for each MLC dielectric ceramic were used to calculate $\mathrm{K}_{\mathrm{Ic}}$ using [3]

$$
\mathrm{K}_{\mathrm{Ic}}=\zeta\left[\frac{\mathrm{E}}{\mathrm{H}}\right]^{1 / 2}\left[\frac{\mathrm{P}}{\mathrm{c}^{3 / 2}}\right]
$$

where $\zeta$ is a material independent constant for the Vickers indenter. The values of $E$ and $H$ used in Eq. 1 were those measured with the MPM-generated crack-free indents. Twenty indents were applied at high loads to produce cracks, and up to four cracks were produced per indent. However, many indents did not have four cracks, so the number of fracture toughness values comprising the average was less than eighty for all three sets.

The analyses of these properties using a Vickers indenter with a conventional microhardness tester is somewhat typical; however, such indents generated with a conventional microhardness tester (and typically used loads) would be much larger than the sizes of the cover layers, margins, and end margins in these MLCs. The indents generated with a MPM are much smaller than those generated with a standard hardness tester (a few microns versus hundreds of microns), so they are more amenable for MLC micromechanical testing. The investigators of this study are not aware (i.e., no literature references found) of the MPM being used by others to mechanically characterize the various dielectric constituents in a MLC, so the described test technique in combination with the analyses in this report may be the first of its kind. 
(a)

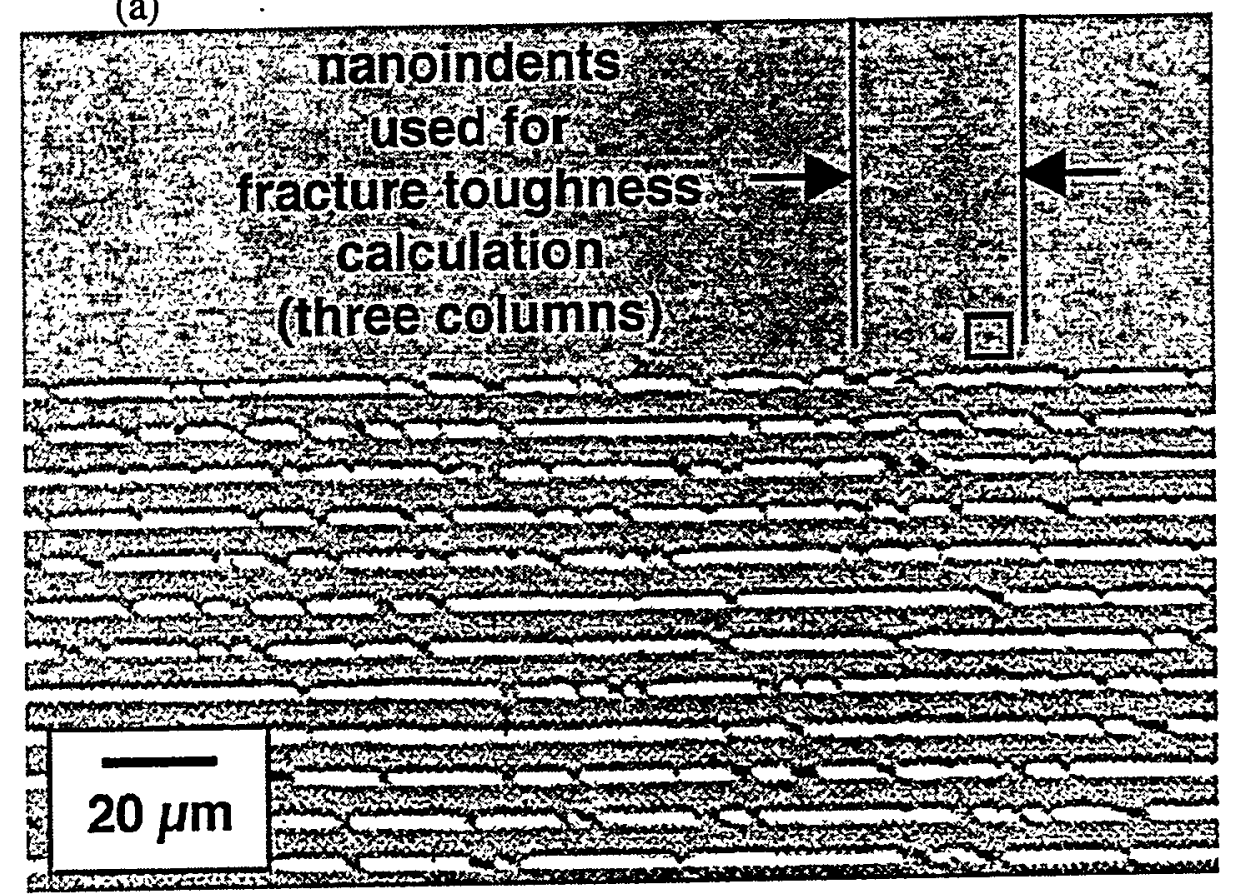

(b)

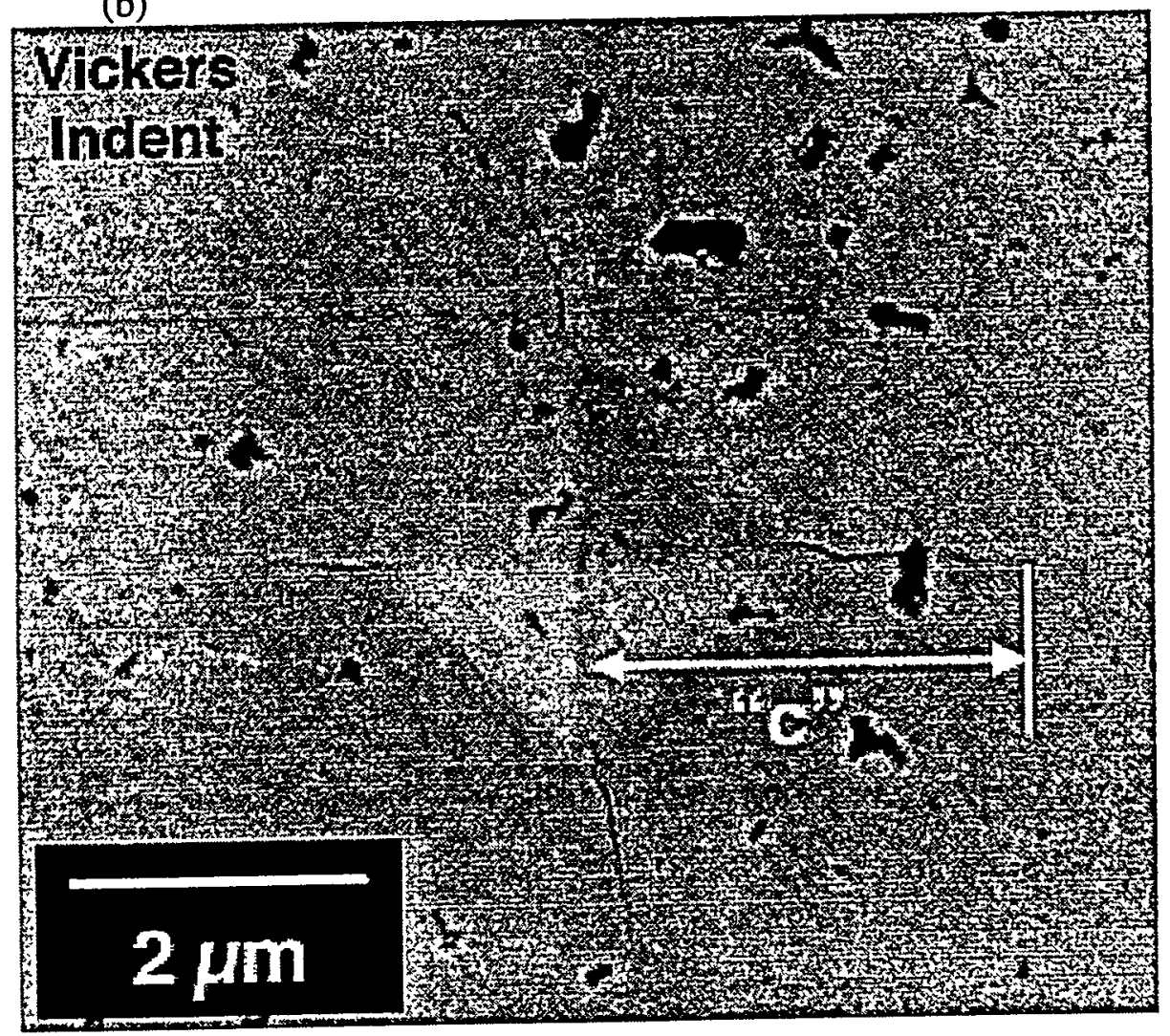

Figure 8. Example of indent pattern in MLC cover layer (a). An enlargement of the box in (a) shows the Vickers indent and the produced cracks (b) whose lengths were used in the determination of fracture toughness. 


\subsubsection{Calculation of Strength Distribution}

Early in the study, one of the three MLC manufacturers supplied large $\mathrm{BaTiO}_{3}$ blanks to this project for flexure strength testing. Such tests have been performed on $\mathrm{BaTiO}_{3}$ in the past [4-5]. The motive behind this was to generate a Weibull strength distribution that could be used as input in the reliability or failure probability prediction of a cover layer subjected to residual stress. The results of that study appear in Reference [6], and failure probability as a function of "stress-freetemperature" in the MLC was predicted.

A significant problem was then identified with the strength data used in Reference [6]. During specimen fractography and flaw identification of the tested flexure specimens, it was observed that a relatively large pore was typically the strength-limiter in the $\mathrm{BaTiO}_{3}$ blanks. The pores were a consequence of the special processing that went into making the large blanks for the flexure testing: they were of a flaw type and size that does not exist in the dielectrics in the actual MLCs. Consequently, the generated flexure strength data was not an appropriate input source for the failure probability analysis because it did not represent the strength of the $\mathrm{BaTiO}_{3}$ dielectric within the MLC. An important conclusion results from this; namely, unless one performs fractography on fractured $\mathrm{BaTiO}_{3}$ specimens, then the measured strength data cannot be deemed as representative unless the same strength-limiting flaw type is limiting the strength of both the specimens and the component of interest. For design of structural ceramics, it is widely recognized that strength data is valuable only if it is "censored" through fractography and the strength distributions are then associated with a particular flaw type. Uncensored strength data is useful for qualitative comparisons of materials, but it is useless for probabilistic ceramic design.

The dielectric ceramic cover layers, margins, and end margins are so small that their isolation and valid strength testing via conventional testing means (e.g., flexure, tension) is extremely difficult. Obtaining a valid strength test becomes elusive as the necessary strength test fixtures and specimens become smaller and smaller as described in Reference [7]. Consequently, efforts were initiated to attempt to "calculate" a Weibull strength distribution from the measurement of potential strength-limiting flaw size distributions (using image analysis) and the use of the Griffith equation. Such an approach has been used with strength prediction of an alumina [8] and a silicon carbide [9] and has satisfactorily correlated with actual strength measurements. 
The dielectric ceramic in all three MLC sets contained two different and concurrent flaw types that were studied as potential strength-limiters: pores and secondary phase "inclusions" (see Fig. 9 for a representative microstructure that shows both). The secondary phase inclusions typically were a small volume of material that was devoid of an additive such as bismuth as identified using SEM/EDS. The pore- and inclusion-size distributions were quantified using an in-house developed LabView ${ }^{T M}$ image digitization program. It was assumed that the pores present on the sectioned and polished surface were intrinsic to the dielectric ceramic and not a consequence of "grain pull out" from the polishing procedure. Six SEM pictures were taken of the sectioned and polished dielectric ceramic in each of the three MLC sets, and then were image-analyzed to determine a "flaw" size distribution. Each pore or secondary phase inclusion was assumed to have a spherical shape. The "flaws" in each picture were then pooled with those in the other five pictures for each MLC set. The magnification of each image was 2000x (1024 x 1024 pixels), and each picture sampled an area which was $45 \times 45 \mu \mathrm{m}$ resulting in a per-pixel-area (i.e., resolution) of approximately $44 \mathrm{~nm}^{2}$.

Strengths were then calculated from the measured flaw size distributions; namely, an ith strength limited by each ith flaw was determined. If the size of a flaw, its geometry, and the fracture toughness of the material are known, then the critical maximum tensile stress or strength $(\sigma)$ may be described according to the Griffith criterion:

$$
\sigma=\frac{\mathrm{K}_{\mathrm{Ic}}}{\mathrm{Y} \sqrt{\mathrm{c}}}
$$

where $\mathrm{K}_{\mathrm{lc}}$ is the material's fracture toughness, $\mathrm{Y}$ is a crack geometry correction factor $(\mathrm{Y}=1.13$ for a volume-located pore or inclusion [10]), and $\mathrm{c}$ is the radial size of the pore or inclusion (assuming a spherically-shaped flaw). The average fracture toughness for each MLC dielectric ceramic was used in Eq. 2 for the calculation of $\sigma$. 


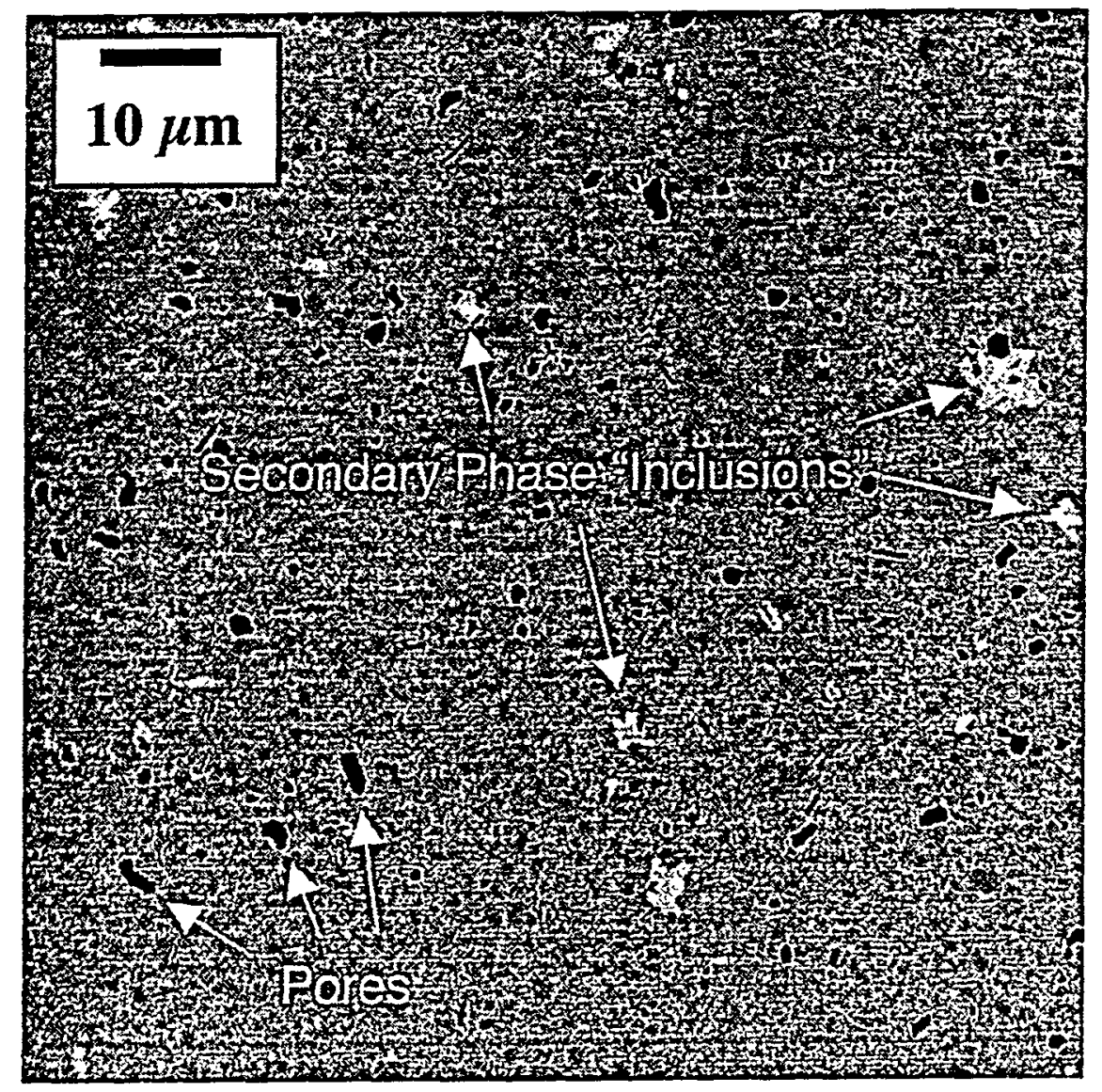

Figure 9. The size distribution of two potential strength-limiting flaw types were measured: pores and secondary phase "inclusions."

All the strengths were then fitted to a two-parameter Weibull distribution using maximum likelihood analysis in the statistical computer program called "CERAMIC" [11]. The expression relating the probability of failure to stress for volume flaws acting as strength-limiters is

$$
P_{f}=1-\exp \left[-k_{v} v\left(\frac{\sigma}{\sigma_{o}}\right)^{m}\right],
$$

where $P_{f}$ is the probability of failure, $k_{v}$ is a "load factor" which is descriptive of the stress gradient ( $\mathrm{k}_{\mathrm{v}}=1$ in pure tension), $\mathrm{V}$ is the volume, $\mathrm{m}$ is the Weibull modulus and $\sigma_{\mathrm{o}}$ is the Weibull scaling parameter. The function describes higher failure probabilities for higher applied stresses and larger volumes, with the latter being a recognized characteristic of monolithic ceramics. The Weibull modulus and scaling parameter represent the overall Weibull distribution, so these parameters were determined for each pore- and inclusion-size distribution. To facilitate the comparisons of these 
distributions for the dielectric ceramics in the three MLC sets, the distributions were scaled to a unit volume (i.e., $\mathrm{V}=1 \mathrm{~mm}^{3}$ in Eq. 2) and then graphed assuming a uniaxial application of tensile stress (i.e., $\mathrm{k}_{\mathrm{v}}=1$ in Eq. 2) for each dielectric ceramic.

\section{RESULTS AND DISCUSSION}

\subsection{Ceramic "Window of Design"}

Ceramic materials are much stronger in compression than they are in tension; in fact, the compressive strength of ceramics is often more than an order of magnitude greater. This characteristic is unlike most metals which have approximately equivalent tensile and compressive strengths. Consequently, a mechanically robust ceramic component will undoubtedly be designed so that it will be subjected to minimal tensile stresses, or under ideal (and rarely occurring) circumstances, will be designed so that they are subjected to only compressive stresses $(e . g$. , an arch).

An illustration of a "window of design" is shown in Fig. 10 for ceramic materials. Several parameters can affect the location of where one's component is located in the window. Much of the discussion that follows will be in reference to the upper portion of the design window; namely the size of the tensile stress region. Factors such as geometry, fracture toughness, strength, strength-size-scaling, residual stress, how cover layer knit lines are subjected to service, and the severity of glass frit penetration at the termination metal ends can all affect mechanical robustness, and their roles are described or reviewed.

\subsection{Geometrical Issues \& Board Flexure}

The values of the MLC dimensions are listed in Table 1 (and refer to Fig. 3). The external dimensions of the MLCs are represented by dimensions "A," "I," and "M." For the "0805" MLC designation, the " $\mathrm{T}$ " and " $\mathrm{M}$ " dimensions represent the " 0805 " and "08도," respectively, with the 08 and 05 representing $0.080 \mathrm{in} .(2.03 \mathrm{~mm})$ and $0.050 \mathrm{in} .(1.27 \mathrm{~mm})$, respectively. The measured "T" and " $M$ " values for each of the three MLCs were within \pm 0.004 in. $(0.10 \mathrm{~mm})$ of their manufactured designated values. 


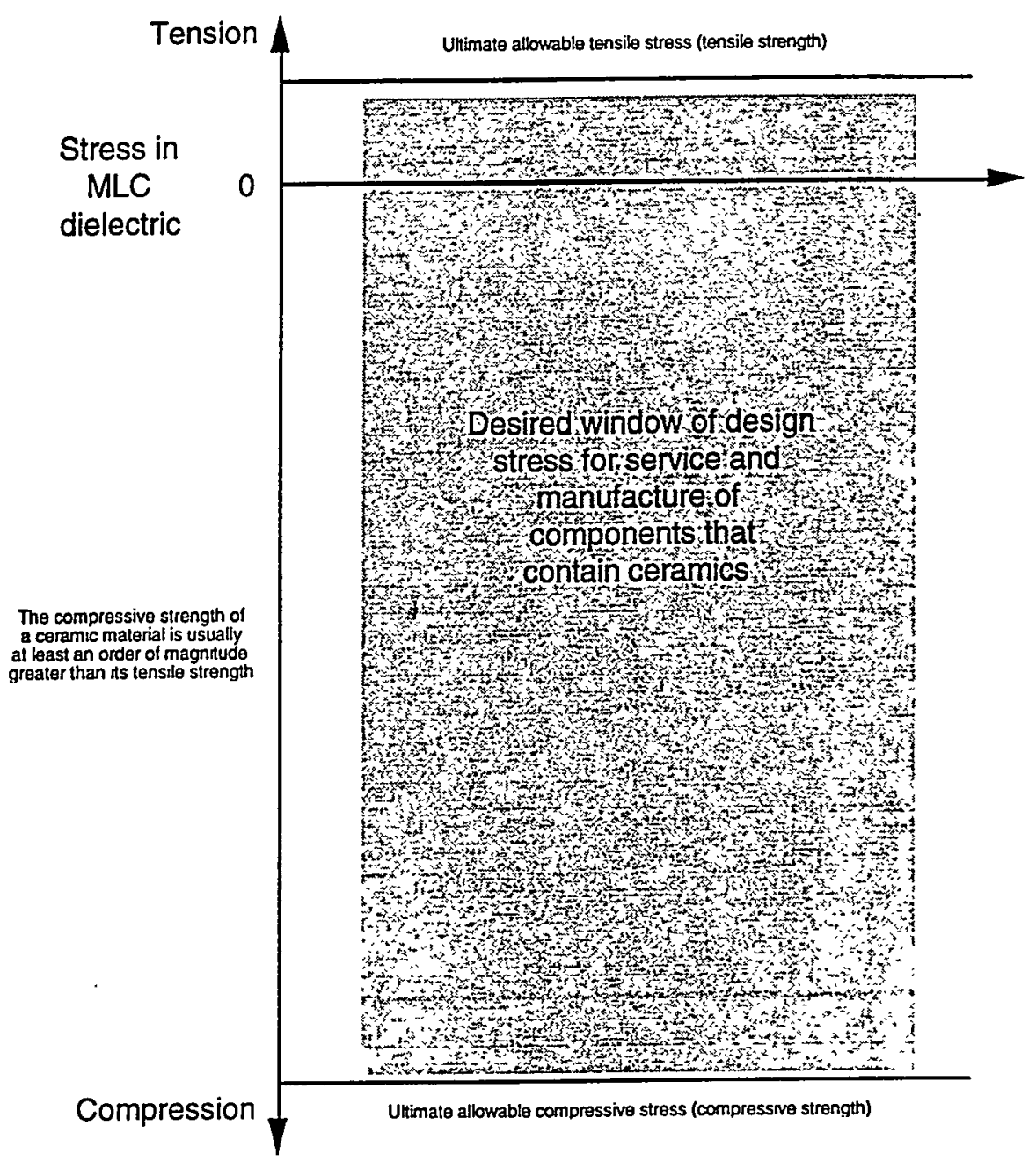

Figure 10. Ceramic components are more mechanically robust if they are designed to be subjected to compressive stresses. The design window is asymmetric because ceramics are able to withstand higher compressive stresses than tensile stresses.

The centering of the electrodes in the MLC was examined by comparing the thickness of the two opposite cover layers, margins, or end margins on any one of the three planes (see Fig. 5). The thicknesses of these dielectric ceramic sections are listed in Table 2 for each of the MLCs. None of the three MLCs had electrodes that were well-centered in all three orientations, although the MLC-C's electrodes were the most centered of the three. 
The number of electrodes, the distance between parallel plates, and the size of the parallel plates are summarized in Table 3. The dielectric thickness between each pair of electrodes in the MLC-C is the smallest of the three, with the MLC-A dielectric slightly thicker, and the MLC-B dielectric being the thickest. The MLC-A has a larger overall plate area (\# of electrode "plates" times the area per "plate") and was approximately $20 \%$ more than that in both the MLC-B and MLC-C.

Table 1. Dimensions of multilayer capacitors and their dielectrics and electrodes corresponding to Fig. 4.

\begin{tabular}{|c|c|c|c|}
\multicolumn{1}{c}{} & \multicolumn{1}{c}{$\begin{array}{c}\text { MLC-A } \\
\text { Dimension }\end{array}$} & $\begin{array}{c}\text { MLC-B } \\
(\mathrm{mm})\end{array}$ & $\begin{array}{c}\text { MLC-C } \\
(\mathrm{mm})\end{array}$ \\
\hline $\mathrm{A}$ & 0.988 & 1.225 & 0.837 \\
\hline $\mathrm{B}$ & 0.077 & 0.187 & 0.141 \\
\hline $\mathrm{C}$ & 0.842 & 1.000 & 0.685 \\
\hline $\mathrm{D}$ & 0.922 & 1.177 & 0.791 \\
\hline $\mathrm{E}$ & 0.082 & 0.050 & 0.053 \\
\hline $\mathrm{F}$ & 0.341 & 0.308 & 0.267 \\
\hline $\mathrm{G}$ & 1.828 & 1.757 & 1.776 \\
\hline $\mathrm{H}$ & 2.015 & 1.942 & 1.994 \\
\hline $\mathrm{I}$ & 2.098 & 1.992 & 2.047 \\
\hline $\mathrm{J}$ & 1.993 & 1.892 & 1.941 \\
\hline $\mathrm{K}$ & 0.252 & 0.216 & 0.286 \\
\hline $\mathrm{L}$ & 1.060 & 0.995 & 1.084 \\
\hline $\mathrm{M}$ & 1.261 & 1.180 & 1.251 \\
\hline
\end{tabular}

Table 2. Dimensions of dielectric cover layers and margins.

\begin{tabular}{|c|c|c|c|}
\multicolumn{1}{c}{ Dimension } & \multicolumn{1}{c}{$\begin{array}{c}\text { MLC-A } \\
(\mathrm{mm})\end{array}$} & $\begin{array}{c}\text { MLC-B } \\
(\mathrm{mm})\end{array}$ & $\begin{array}{c}\text { MLC-C } \\
(\mathrm{mm})\end{array}$ \\
\hline $\begin{array}{c}\text { End Margin 1 } \\
(=\mathrm{F}-\mathrm{E})\end{array}$ & 0.259 & 0.258 & 0.214 \\
\hline $\begin{array}{c}\text { End Margin 2 } \\
(=\mathrm{H}-\mathrm{G})\end{array}$ & 0.187 & 0.185 & 0.218 \\
\hline $\begin{array}{c}\text { Cover Layer 1 } \\
(=\text { D-C })\end{array}$ & 0.080 & 0.177 & 0.106 \\
\hline $\begin{array}{c}\text { Cover Layer 2 } \\
(=\mathrm{B})\end{array}$ & 0.077 & 0.187 & 0.141 \\
\hline $\begin{array}{c}\text { Margin 1 } \\
(=\mathrm{K})\end{array}$ & 0.252 & 0.216 & 0.286 \\
\hline $\begin{array}{c}\text { Margin 2 } \\
(=\mathrm{M}-\mathrm{L})\end{array}$ & 0.201 & 0.185 & 0.167 \\
\hline
\end{tabular}


Table 3. Electrode and dielectric layer information.

\begin{tabular}{|c|c|c|c|}
\hline Item & MLC-A & MLC-B & MLC-C \\
\hline $\begin{array}{c}\text { \# of electrodes } \\
/ \\
\# \text { of } \\
\text { dielectrics }\end{array}$ & $54 / 53$ & $48 / 47$ & $45 / 44$ \\
\hline $\begin{array}{c}\text { Center-to- } \\
\text { center distance } \\
\text { between } \\
\text { "parallel } \\
\text { plates" } \\
\text { (microns) }\end{array}$ & 14 & 17 & 12 \\
\hline $\begin{array}{l}\text { Dimensions of } \\
\text { each } \\
\text { "plate" } \\
\text { (mm x mm) }\end{array}$ & $0.81 \times 1.49$ & $0.78 \times 1.45$ & $0.80 \times 1.51$ \\
\hline $\begin{array}{l}\text { Area of } \\
\text { each } \\
\text { "plate" } \\
\left(\mathrm{mm}^{2}\right)\end{array}$ & 1.20 & 1.13 & 1.20 \\
\hline $\begin{array}{c}\text { Total } \\
\text { "plate" } \\
\text { area } \\
\left(\mathrm{mm}^{2}\right)\end{array}$ & 63.6 & 53.1 & 52.8 \\
\hline
\end{tabular}

The geometry of a surface-mounted MLC subjected to board flexure is an important consideration. A flexed board will transfer stress (more of a displacement-controlled event rather than a stresscontrolled event) through the solder joint to the MLC as shown in Fig. 11. For any transferred force or displacement, the geometry of the MLC will effect what the magnitude of the stress is within it. A board flexure direction as shown in Fig. 11 will transfer tensile stress to the MLC. and is more problematic than if the board is flexed in the opposite direction. Because of the surface mounting and the nature of the solder bonding shown in Fig. 11, the applied tensile stress in such a circumstance is greatest in the lower portion of the MLC and lessens along the height. A board flexure opposite to that shown in Fig. 11 will subject the MLC to compression. The dielectric ceramics in MLC's are more mechanically robust when subjected to compression loading as illustrated in Fig. 10.

Non-centering of the electrodes may result in unequal or unanticipated high stress distributions depending on which orientation the MLC is surface-mounted and if it is subjected to board flexure. Unequally sized margins in some orientations can be more problematic than in others. If the surface mounted MLC has cover layers that are not equally sized and the thinner side is mounted down, then that cover layer will be subjected to a higher stress than if the opposite (thicker) cover 
layer were mounted down. For MLCs with square cross-sections, then there is $50 \%$ probability that the margins will be mounted down, so their thickness (as compared to the cover layer thicknesses) then becomes an issue. The effects of off-centered end margins subjected to board flexure are less obvious. Their effects may be more pronounced when subjected to the thermal excursions of soldering (discussed in Section 4.5.4). The occurrence of unanticipated high stress concentrations can be avoided through the attainment of centered electrodes in an MLC.

Qualitatively, (shear and tensile) stresses in a MLC cover layer will be minimized during board flexure if its down-side-mounted thickness is maximized. This is qualitatively portrayed in Fig. 12. If the amount of board flexure is large and its flexure axis known, then rotating the MLC (and its electrical leads) so that its primary length is perpendicular to the board flexure axis will also act to minimize imposed stresses on the cover layers, or another option is to use leadframes for stress relief [12]. This is different than the analysis of Megherhi, et. al, [13] in which electrodes positioned close to the surface were measured to strengthen and toughen the whole multilayer composite structure. This discussion posed in this paragraph pertains to the cover layer (or one constituent in a multilayer composite structure).
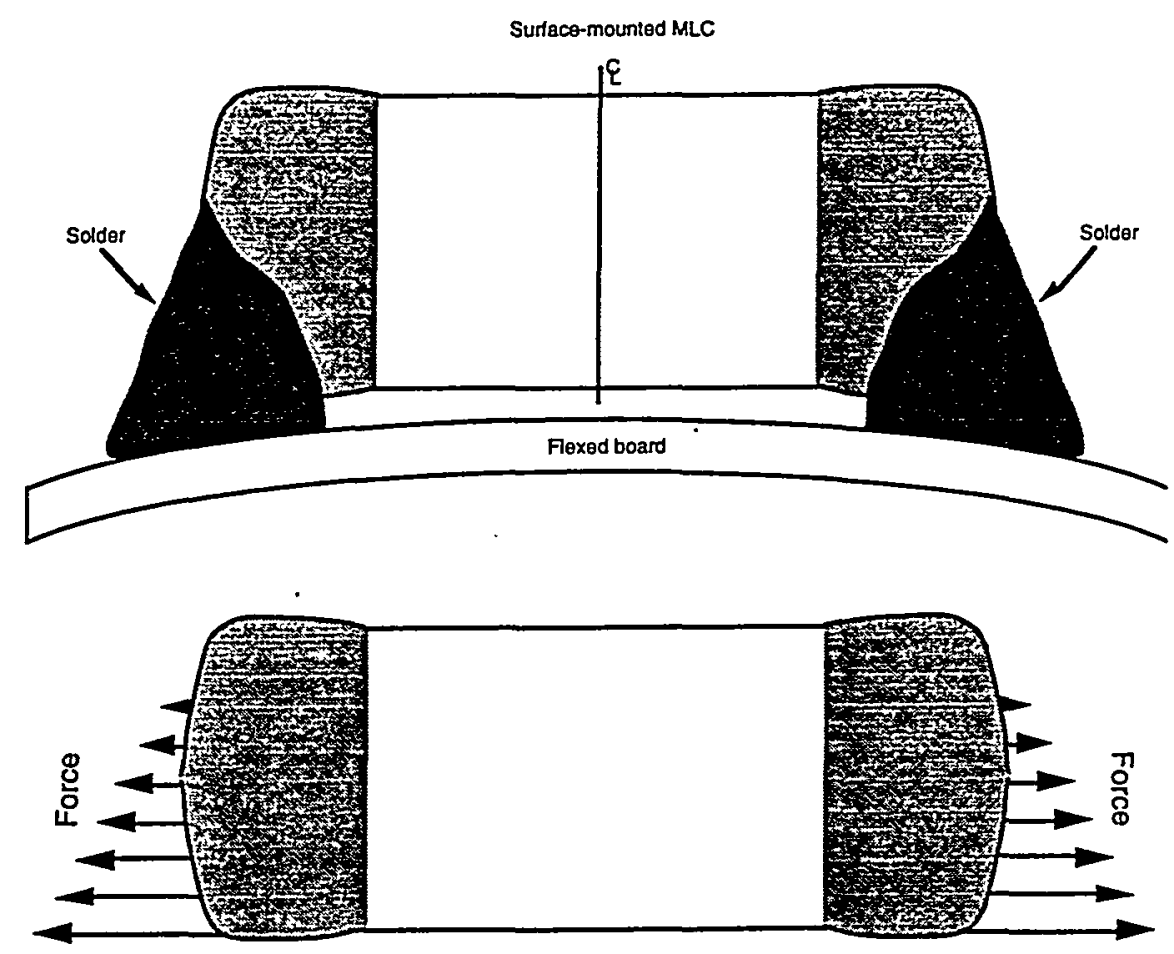

Figure 11. Schematic of a surface-mounted MLC on a flexed board (top). The board's curvature transfers a tensile force through the solder and ultimately to the MLC (bottom). This results in a relatively high shear (and tensile) stress near the bottom of the MLC. 


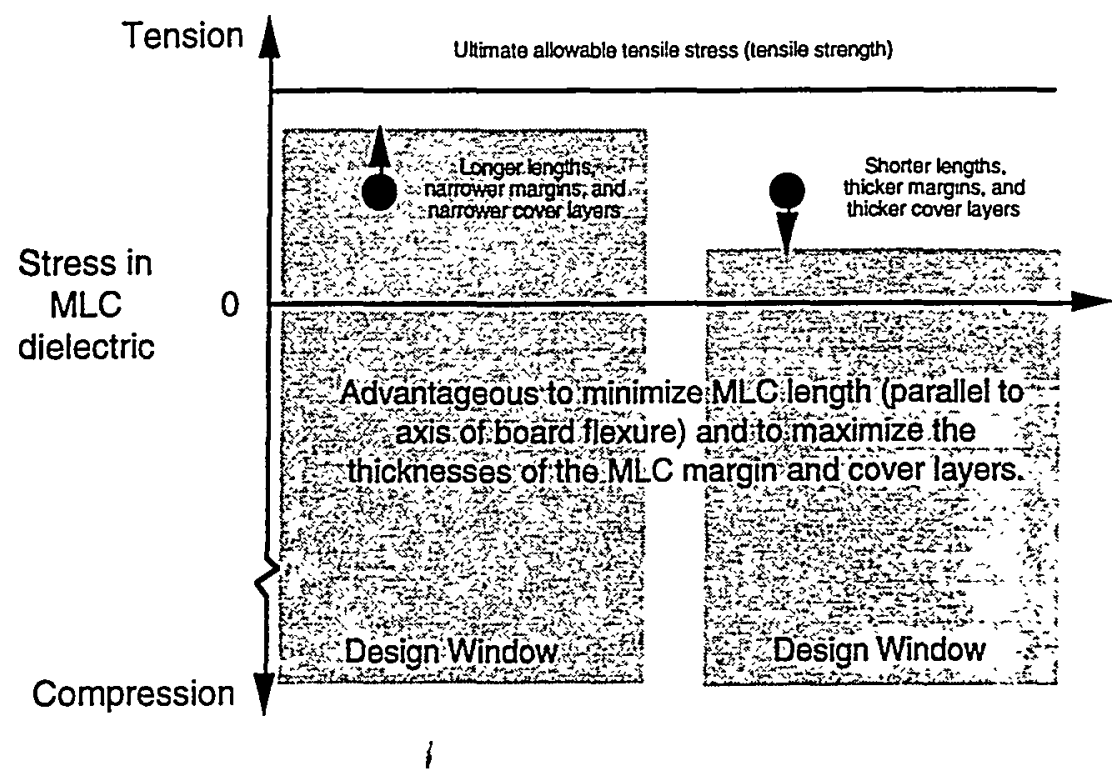

Figure 12. The geometry of the MLC's cover layer, margins, and end margins can affect the tensile and shear stress in a surface-mounted MLC that is subjected to board flexure.

\subsection{Mechanical Properties: Seek Maximum Strength and Toughness of the Dielectric}

\subsubsection{Young's Modulus and Hardness}

The Young's modulus of the dielectric ceramic in the MLC-C was slightly higher (203 GPa) than that for the dielectric ceramics in the MLC-A (193 GPa) and MLC-B (192 MPa). The difference between the former and the latter two E's is statistically significant. The hardnesses of the dielectric ceramics in each of the three MLC systems were statistically equivalent. The average $\mathrm{E}$ and $\mathrm{H}$ for the dielectrics in the three investigated MLCs are listed in Table 4, along with their standard deviations.

Although their testing has not been described, the Young's modulus and hardness of the termination metals in each of the three MLCs were also measured but their results were not informative. The termination metal in the MLC-C had the largest Young's modulus, followed in order by MLC-B and MLC-A. The hardnesses of the termination metal in the MLC-C and MLC-B were statistically equivalent, and were larger-valued than the termination metal in the MLC-A. The Young's modulus and hardness of the termination metals in each of the three sets were significantly lower (by more than an order of magnitude) than those of their dielectric ceramics. Additionally, the coefficients of variation (standard deviation divided by average) for the termination metals were much larger than those for the ceramic dielectrics. This large scatter in 
measured values was due to the "composite-like" structure of the termination metal (mixture of brittle particulates and ductile metal) and the indentation of its separate constituents. For this measurement of termination metal hardness, a microhardness tester with its relatively large indenter probably would be more appropriate for it could sample the "composite" hardness.

The Young's modulus of the dielectric ceramic and termination metal in each of the three MLCs are not direct indicators of the potential mechanical integrity of the MLCs. However, their values can provide some insights. Principally, if the dielectric ceramic in a MLC has a relatively large-valued Young's modulus, then the imposed stresses in it will be higher than if its $\mathrm{E}$ were lower-valued (for the same applied strain). The $\mathrm{E}$ of the dielectric in the MLC-C is approximately $5 \%$ larger than the $E$ of the dielectrics in the MLC-A and MLC-B, so stress in the MLC-C would be approximately $5 \%$ more if the three MLCs were subjected to the same amount of strain (e.g., all three mounted MLCs's flexed the same amount on an epoxy board). The differences in stress due to the differences in the dielectric ceramic E's of the three MLCs is probably not significant and not an indicator of predicted mechanical integrity among these three MLCs. The E's of the termination metal provide some insight into their ductile nature; often a lower-valued $E$ for a metal is an indicator that it can deform more readily when subjected to stress. Furthermore, if a termination metal is more ductile, then it can more readily relieve stress concentrations. Utilizing termination metals in the MLC with greater ductility is preferable because minimizing tensile stresses in MLCs will lessen the likelihood of mechanical failure of the dielectric ceramics within them.

The hardness of the dielectric ceramics is also not a direct indicator of the potential MLC mechanical robustness, but its value can also provide some insight into the effects of porosity and grain size on it. Hardness is typically inverse to the amount of porosity. This is often observed and exploited with conventional microhardness testing where the indent samples a very large number of pores and is hundreds of microns in size. However, with indents in the present study only being a few microns in size (see Fig. 8(b)), and only perhaps an order of magnitude larger in size than the pores, the relationship between hardness and porosity at the operating-size-scale of the MPM cannot be readily interpreted. Lastly, the measured hardnesses were more representative of the hardness of the $\mathrm{BaTiO}_{3}$ grains because the MPM produced an indent size that sampled regions consisting of sub-micron grains; conversely, this is not always the case for microhardness testing because its produced large indent size samples many more grains, but also porosity, grain boundaries, etc. 
Qualitatively, if the average pore size is small, then the fracture toughness of the ceramic may be relatively high because crack growth may be inhibited or arrested by the pores. Conversely, if the average pore size is relatively large, then the pores may act as actual strength-limiting flaws with the effect of lowering the strength of the ceramic (to be discussed further in Section 4.3.3). The hardnesses of the dielectric ceramics in the three examined MLCs were in fact equivalent, so if these were active effects, then they were equivalent in the three different dielectric ceramics.

\subsubsection{Fracture Toughness}

The $\mathrm{K}_{\mathrm{Ic}}$ of the MLC-C $(1.53 \mathrm{MPa} \sqrt{\mathrm{m}})$ was larger than that for the MLC-A $(1.36 \mathrm{MPa} \sqrt{\mathrm{m}})$ which in turn was larger than that for MLC-B $(1.11 \mathrm{MPa} / \mathrm{m})$. The fracture toughness of another barium titanate (as measured with microhardness indentation testing) was measured to range from 1 to 1.8 $\mathrm{MPa} V_{\mathrm{m}}$ [4-5]. Fracture toughness in $\mathrm{BaTiO}_{3}$ can depend on several variables including grain size, chemical composition, and crystal structure [1]. The differences among the average fracture toughnesses were statistically significant and conclusive. The average $\mathrm{K}_{\mathrm{lc}}$ for these three MLC systems are listed in Table 4 and shown in Fig. 13.

Ceramics with maximum $\mathrm{K}_{\mathrm{lc}}$ are preferable for load-bearing applications. Dielectric ceramics in MLCs may be subjected to tensile stresses during manufacturing or service, so using a dielectric ceramic with maximum $\mathrm{K}_{\mathrm{Ic}}$ will minimize the likelihood of mechanical failure as schematically shown in Fig. 14. The dielectric ceramic in the MLC-C had the highest $\mathrm{K}_{\mathrm{Ic}}$, while the dielectric ceramic in the MLC-A had the second highest $\mathrm{K}_{\mathrm{Ic}}$ and that in the MLC-B had the lowest. All other things being equal, the dielectric ceramic in the MLC-C would have the best mechanical integrity and would have the lowest likelihood of mechanical failure of the three MLCs if they were subjected to equivalent mechanical loadings. 


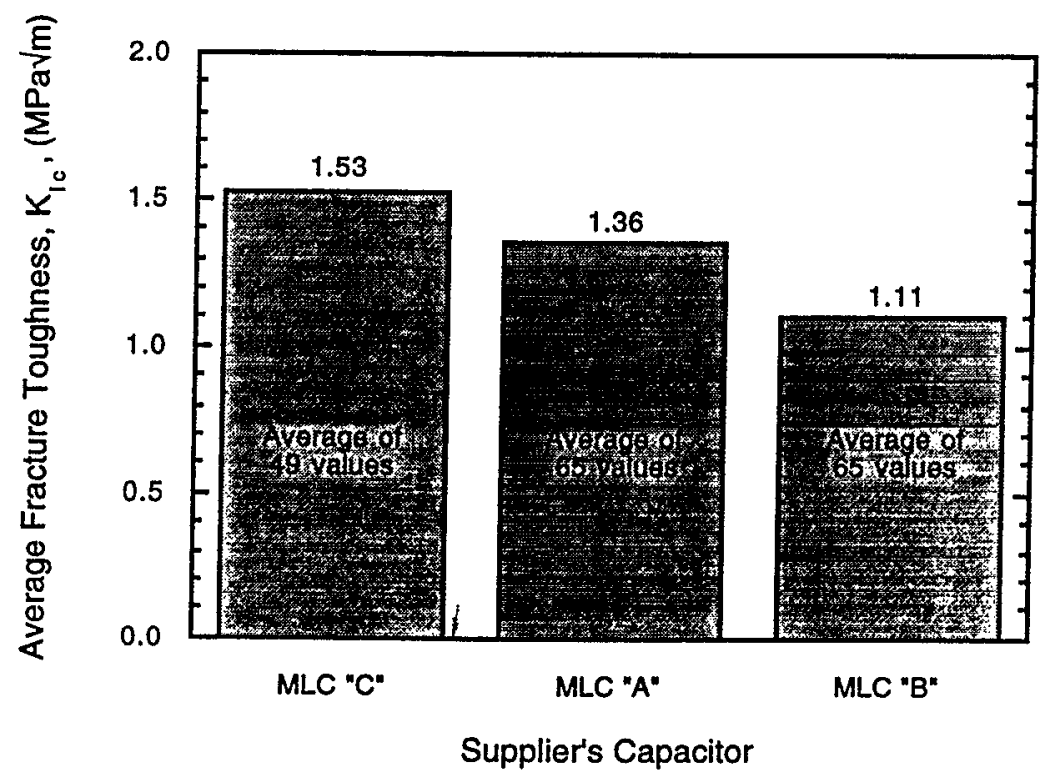

Figure 13. The fracture toughnesses of the dielectrics in the three MLCs were different.

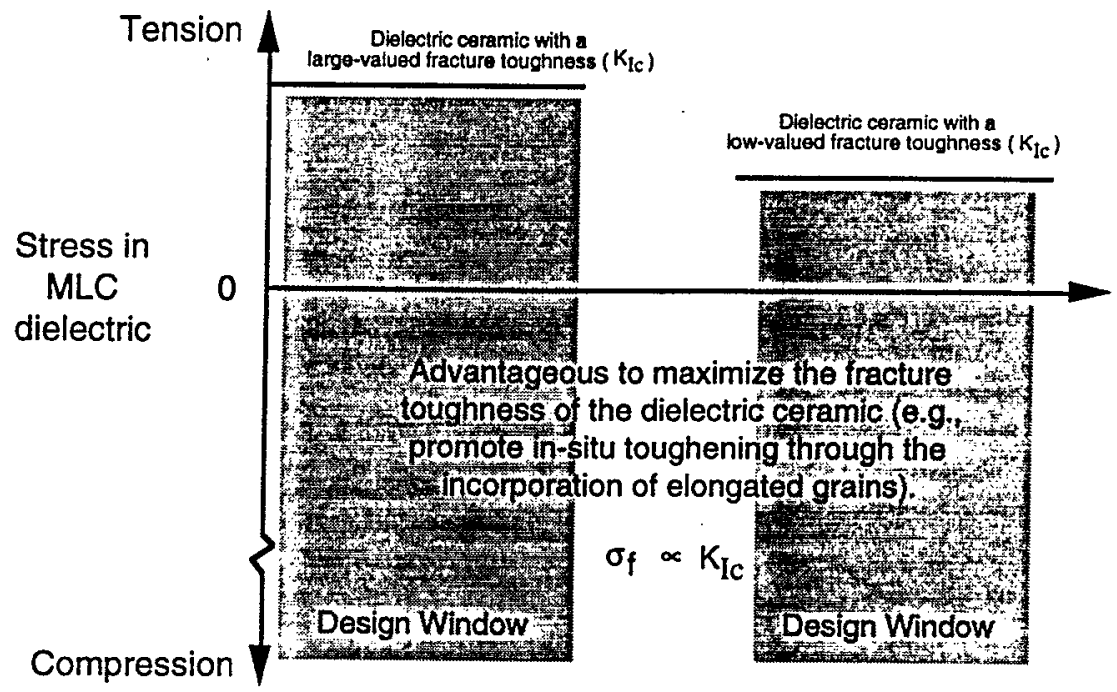

Figure 14. Higher dielectric fracture toughness will result in better mechanical robustness. 
Table 4. Measured mechanical properties of dielectric ceramics.

\begin{tabular}{|c|c|c|c|}
\hline Property & MLC-A & MLC-B & MLC-C \\
\hline $\begin{array}{l}\text { Young's } \\
\text { Modulus, } \\
\mathrm{E}, \\
\text { (GPa) } \\
\text {-Average- }\end{array}$ & $\begin{array}{c}193 \\
40 \text { tests }\end{array}$ & $\begin{array}{c}192 \\
40 \text { tests }\end{array}$ & $\begin{array}{c}203 \\
40 \text { tests }\end{array}$ \\
\hline $\begin{array}{c}\text { Young's } \\
\text { Modulus, } \\
\mathrm{E}, \\
\text { (GPa) } \\
\text {-Stan. Dev.- }\end{array}$ & $\begin{array}{c}8.5 \\
40 \text { tests }\end{array}$ & $\begin{array}{c}9.2 \\
40 \text { tests }\end{array}$ & $\begin{array}{c}7.7 \\
40 \text { tests }\end{array}$ \\
\hline $\begin{array}{c}\text { Hardness, } \\
\text { H, } \\
\text { (GPa) } \\
\text {-Average- }\end{array}$ & $\begin{array}{c}11.3 \\
40 \text { tests }\end{array}$ & $\begin{array}{c}11.3 \\
40 \text { tests }\end{array}$ & $\begin{array}{c}11.9 \\
40 \text { tests }\end{array}$ \\
\hline $\begin{array}{c}\text { Hardness, } \\
\text { H, } \\
(\mathrm{GPa}) \\
\text {-Stan. Dev.- }\end{array}$ & $\begin{array}{c}1.0 \\
40 \text { tests }\end{array}$ & $\begin{array}{c}0.9 \\
40 \text { tests }\end{array}$ & $\begin{array}{c}0.6 \\
40 \text { tests }\end{array}$ \\
\hline $\begin{array}{l}\text { Fracture } \\
\text { Toughness, } \\
\text { KIc } \\
\text { (MPa } \sqrt{m} \text { ) } \\
\text {-Average- }\end{array}$ & $\begin{array}{c}1.36 \\
49 \text { tests }\end{array}$ & $\begin{array}{c}1.11 \\
65 \text { tests }\end{array}$ & $\begin{array}{r}1.53 \\
65 \text { tests } \\
\end{array}$ \\
\hline $\begin{array}{l}\text { Fracture } \\
\text { Toughness } \\
\text { KIc } \\
\text { (MPa } \sqrt{m}) \\
\text {-Stan. Dev.- }\end{array}$ & $\begin{array}{c}0.29 \\
49 \text { tests }\end{array}$ & $\begin{array}{c}0.28 \\
65 \text { tests }\end{array}$ & $\begin{array}{c}0.47 \\
65 \text { tests }\end{array}$ \\
\hline
\end{tabular}

\subsubsection{Strength Distributions}

The concentration of each possible strength-limiting flaw in the dielectric ceramics was different for the three MLCs. The concentration of the pores in the MLC-B dielectric ceramic was relatively low compared to the other two MLCs (which is represented by the number of identified pores which are summarized in Table 5), while the concentration of secondary phase inclusions was relatively high in MLC-B compared to MLC-A and MLC-C.

The resulting strength distribution parameters for the pores and inclusions are summarized in Table 5. The Weibull moduli and scaling parameters for dielectric ceramic strengths limited by pore flaws are statistically equivalent for all three MLCs, and this is graphically portrayed in Fig. 15(a). The dielectric ceramic in the MLC-B had a slightly higher-valued Weibull modulus among the three MLCs indicating that its pore size distribution was the tightest; however, its 
scaling parameter (a variable linked to average strength) was the lowest of the three, which may indicate that its average pore size was the largest.

The Weibull moduli and scaling parameters were lower for all three materials when inclusions were assumed to be the strength-limiting flaw (versus when pores were viewed as such), and this is illustrated in Fig. 15(b). The Weibull modulus for the dielectric ceramic in the MLC-A was the highest of the three MLCs signifying that the inclusion-size distribution was the tightest. The largest differences existed in the scaling parameters for the strengths limited by inclusion size. The scaling parameter for the dielectric ceramic in the MLC-C was significantly higher than that for the MLC-A dielectric ceramic which in turn was higher than the MLC-B dielectric ceramic.

The scaling parameter is a direct descriptor of strength - they both follow the same trend; namely, a stronger material will have a larger-valued scaling parameter and a larger design window in the tensile region shown in Fig. 16. The scaling parameter has peculiar-looking units due to its use in Eq. 3. One may determine the strength from the scaling parameter if the material's Weibull modulus, its volume, and stress gradient are known; such an exercise was conducted and was illustrated in Figs. 15(a)-(b). The graphed strength distributions in Figs. 15(a)-(b) are representations of the Weibull parameters in Table 5 when a unit volume of each dielectric ceramic is tested in uniaxial tension. Pores and inclusions are viewed as concurrent and non-interacting flaws in these analyses. The scaling parameter values for the strengths limited by inclusion-size are smaller than the scaling parameter values for strengths limited by pore-size; consequently, the inclusions and their larger sizes will limit strength more than the pores. Based on the scaling parameter of the strength distributions, the dielectric ceramic in the MLC-C would be the strongest, followed in turn by the MLC-A and MLC-B dielectric ceramics.

In all the dielectric ceramics in these three MLCs, it is not known if the considered secondary phase inclusion flaw is actually a flaw. If any mismatch between the primary and secondary phases results in a stress concentration about the secondary phase inclusion (e.g., that caused by a possible thermal expansion mismatch), then this considered inclusion indeed may be a strengthlimiting flaw [14]. This possibility was the motivation behind quantifying the inclusion-size distribution and its subsequent strength distribution in the present study.

Lastly, $\mathrm{BaTiO}_{3}$ ceramics have been shown to be susceptible to moisture-induced slow crack growth [15] which is a fatigue mechanism. This effect was not considered in the presently described strength calculations. Its effect would be to shift the shown curves in Figs. 15(a)-(b) to the left (i.e., to lower failure stresses) as time progressed. 
(a)

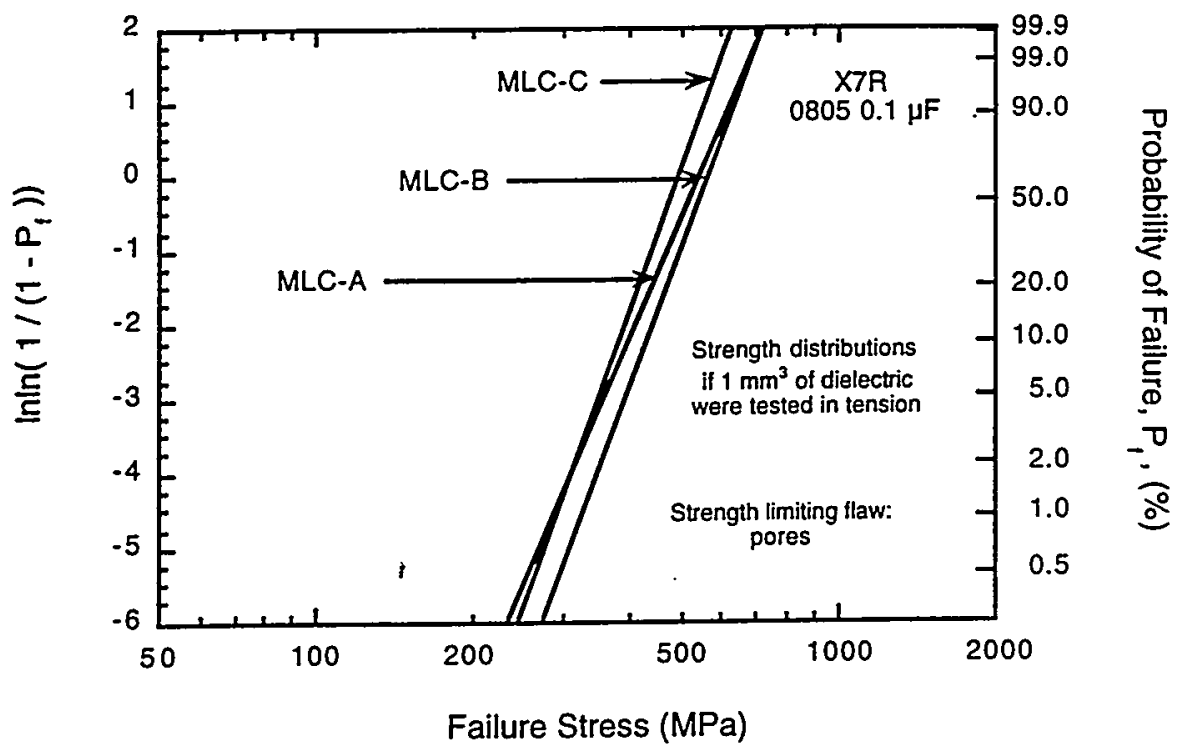

(b)

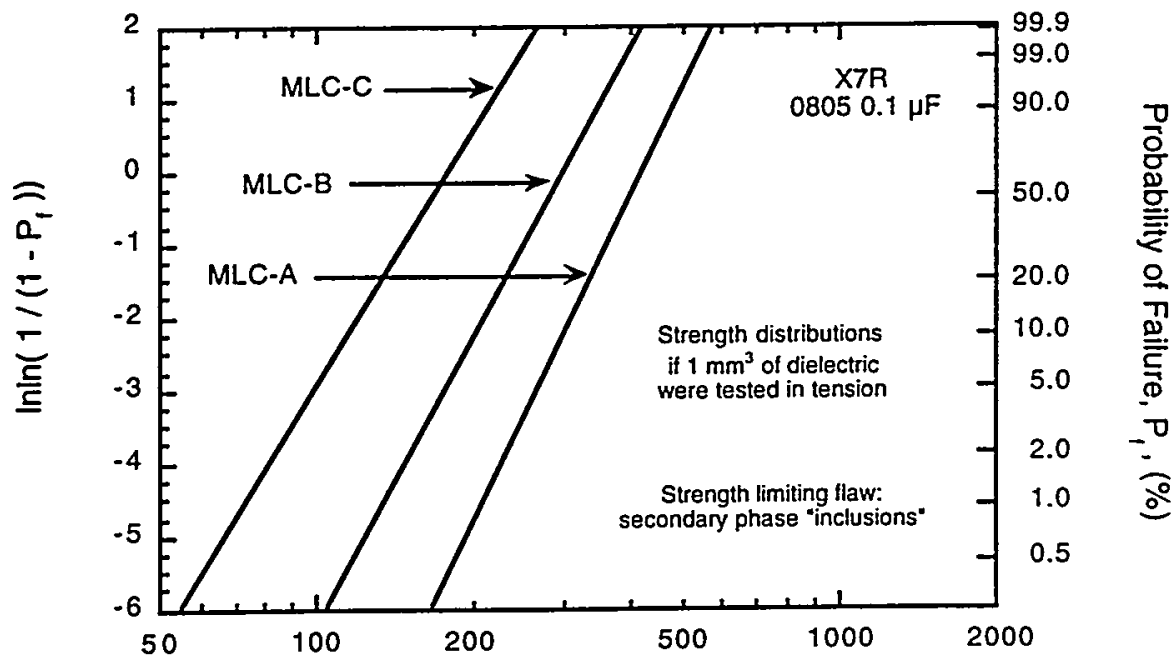

Failure Stress (MPa)

Figure 15. Predicted strength distribution if (a) pores and (b) secondary phase inclusions were the strength-limiting flaw. 


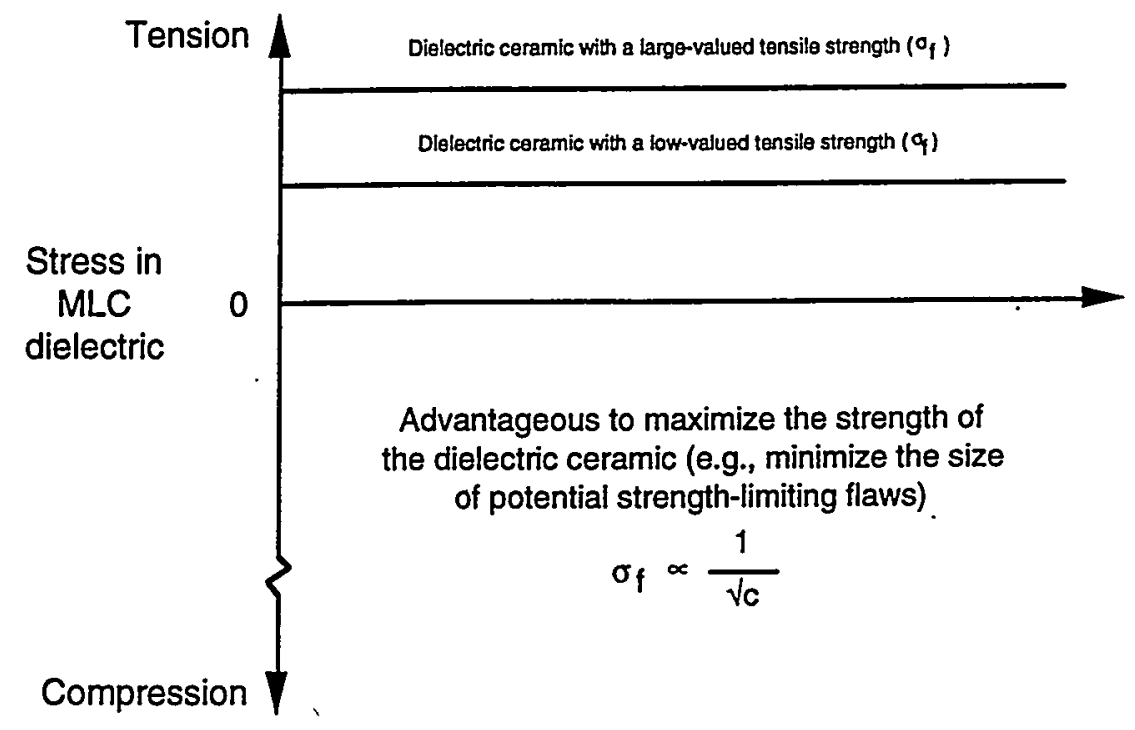

Figure 16. Higher dielectric tensile strength will result in better mechanical robustness.

Table 5. Values of Weibull parameters for the calculated strength distributions.

\begin{tabular}{|c|c|c|c|}
\hline Parameter & MLC-A & MLC-B & MLC-C \\
\hline $\begin{array}{c}\text { Pore } \\
\text { Weibull } \\
\text { modulus } \\
\mathrm{m} \\
( \pm 95 \%) \\
\text { [\# of datapoints] }\end{array}$ & $\begin{array}{c}8.2 \\
(7.4,9.0) \\
{[242]}\end{array}$ & $\begin{array}{c}8.6 \\
(7.2,10.0) \\
{[89]}\end{array}$ & $\begin{array}{c}7.2 \\
(6.8,7.7) \\
{[517]}\end{array}$ \\
\hline $\begin{array}{c}\text { Pore } \\
\text { Scaling } \\
\text { parameter } \\
\sigma_{\circ} \\
\text { MPa-mm } \\
( \pm 95 \%) \\
{[\# \text { of datapoints] }}\end{array}$ & $\begin{array}{c}564 \\
(480,647) \\
{[242]}\end{array}$ & $\begin{array}{c}492 \\
(378,604) \\
{[89]}\end{array}$ & $\begin{array}{c}541 \\
(481,601) \\
{[517]}\end{array}$ \\
\hline $\begin{array}{c}\text { Inclusion } \\
\text { Weibull } \\
\text { modulus } \\
\text { m } \\
( \pm 95 \%) \\
\text { [\# of datapoints] }\end{array}$ & $\begin{array}{c}5.8 \\
(5.2,6.5) \\
{[75]}\end{array}$ & $\begin{array}{c}5.1 \\
(4.7,5.5) \\
{[405]}\end{array}$ & $\begin{array}{c}4.6 \\
(4.2,4.9) \\
{[75]}\end{array}$ \\
\hline $\begin{array}{c}\text { Inclusion } \\
\text { Scaling } \\
\text { parameter } \\
\sigma_{\circ} \\
\mathrm{MPa}^{\circ} \mathrm{mm}^{3 / \mathrm{m}} \\
( \pm 95 \%) \\
{[ \pm \text { of datapoints }]} \\
\end{array}$ & $\begin{array}{c}295 \\
(228,367) \\
{[75]}\end{array}$ & $\begin{array}{c}179 \\
(147,214) \\
{[405]}\end{array}$ & $\begin{array}{c}421 \\
(287,567) \\
{[75]}\end{array}$ \\
\hline
\end{tabular}




\subsection{Does "Classical" Ceramic Design Apply?}

The probabilistic design of structural ceramic components involves the consideration of Weibull mechanical strength distributions of the ceramic material and its strength-size-scaling to the component that is at a known or proposed stress state. For more typical structural applications, strength data is often generated with standard flexure bars and then scaled to larger-sized components, such as a diesel engine valve [16-17] or gas turbine engine component [11]. However, due to the small size of the ceramic dielectric cover layers and margins in MLCs, the direction of size-scaling is the opposite because one would rather test larger, more convenientlysized specimens for strength.

Further distinguishing ceramic component design from that of metals or polymers is the use of stress results from commonly used finite element analysis (FEA). For example, for metal component design, von Mises stresses are often analyzed because of metal's propensity to fail in shear and because of metal's equivalence of tensile and compressive yield strengths. For ceramics, designers focus primarily on the first principal tensile stresses because it is they that will limit mechanical performance (and not compressive stresses) as illustrated in Fig. 10. Multilayer capacitor suppliers have performed FEA on MLCs, such as the stress state analysis of MLCs when subjected to board flexure [18]; however, only the magnitude of the tensile stresses in the dielectric ceramics within the MLC are of interest, not the compressive stresses.

In this section, how the Weibull modulus affects the window of design and strength-size scaling is presented. If one were to generate meaningful Weibull strength data of the dielectric ceramic material, then aspects for classical ceramic component design would be applicable for the ceramic cover layers and margins: so the answer to this section's question would be "yes." A problem of acquiring representative bulk dielectric ceramic materials was encountered by the authors and was described in Section 3.2.2, so the success of probabilistic design is first predicated on using meaningful strength data. If strength data is not a result of representative strength-limiting flaws in the ceramic material, then no design algorithm will produce a valid reliability prediction. 


\subsubsection{Weibull Distribution}

A large-valued Weibull modulus is preferred because it provides a larger window of design than a small-valued Weibull modulus (for the same characteristic strength). This effect is illustrated in Fig. 17. A large-valued Weibull modulus represents a narrow bandwidth of measured strengths, and it is analogous to a small standard deviation for a Gaussian distribution.

There would be a larger window of design for the dielectric ceramics if their strengths were to be limited by pores than by inclusions. The Weibull modulus for strengths limited by pores was approximately 8 while it was approximately 5 for strengths limited by inclusions for the dielectric ceramics in the three MLCs (see Table 5). The higher modulus for the pores was also portrayed in Fig. 15 by its smaller range of failure stresses (compared to the range from inclusions).

\subsubsection{Strength-Size Scaling}

A large-valued Weibull modulus is also beneficial for probabilistic design because the strength-size scaling effect is less significant than for a ceramic with a low-valued modulus (see Fig. 18(a)). Strength-size scaling is also often referred to as "the weakest link" effect in ceramics; namely, a long chain will only be as strong as its weakest link, and breaking a long chain will create two chains that are both stronger than the original. For strengths limited by volume flaws, strengthsize scaling (for an equal probability of failure and loading factor) is represented by [11]

$$
\frac{\sigma_{a}}{\sigma_{b}}=\left[\frac{V_{b}}{V_{a}}\right]^{1 / m}
$$

where $\sigma_{\mathrm{a}}$ and $\sigma_{\mathrm{b}}$ are the failure stresses for components "a" and " $\mathrm{b}$ " and $\mathrm{V}_{\mathrm{a}}$ and $\mathrm{V}_{\mathrm{b}}$ are the component volumes. The effect of the Weibull modulus value on the scaling is further illustrated in the example shown in Fig. 18(b). Doubling the size of a ceramic component can lessen its strength by $13 \%$ for a Weibull modulus of 5 while its strength will only lessen by $3 \%$ if its value were 25 . 


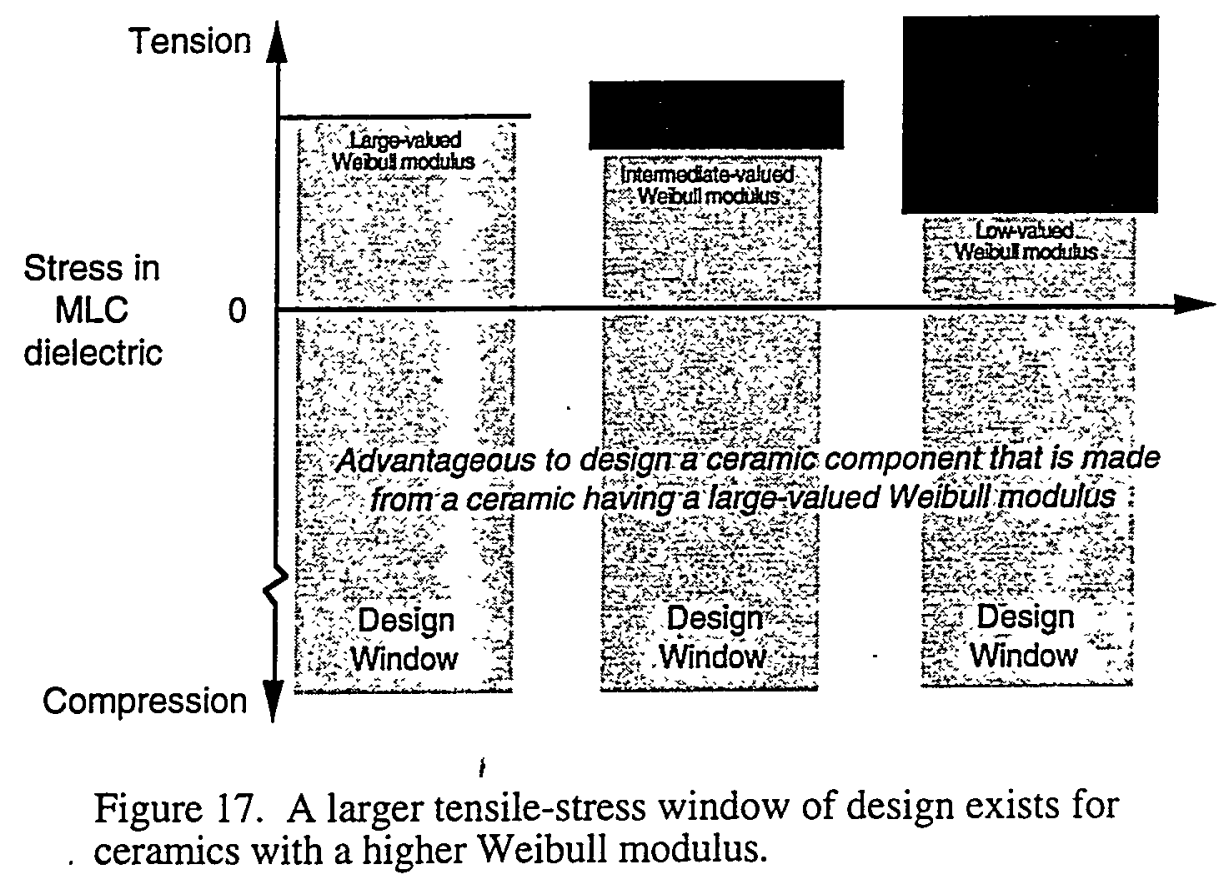

Analogously, for strengths that are limited by surface flaws (e.g., machining damage, scratches on glass), the strength-size scaling is a function of the amount of surface area. The strength-size scaling in this circumstance is represented by (again, for equal probabilities of failure and loading factors)

$$
\frac{\sigma_{a}}{\sigma_{b}}=\left[\frac{A_{b}}{A_{a}}\right]^{1 / m}
$$

where $A_{a}$ and $A_{b}$ are areas of components "a" and "b." Like for volume flaws that were strengthlimiters, it is advantageous to have a large-valued Weibull modulus that describes a strength distribution limited by surface flaws. 
(a)

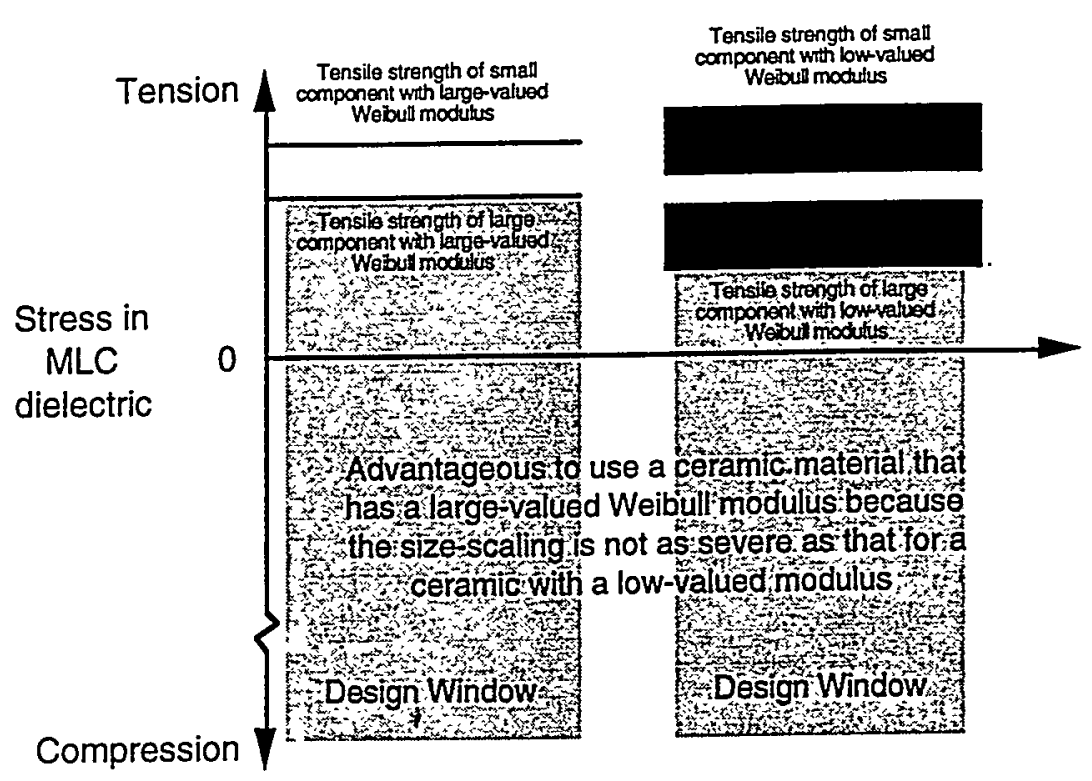

(b)

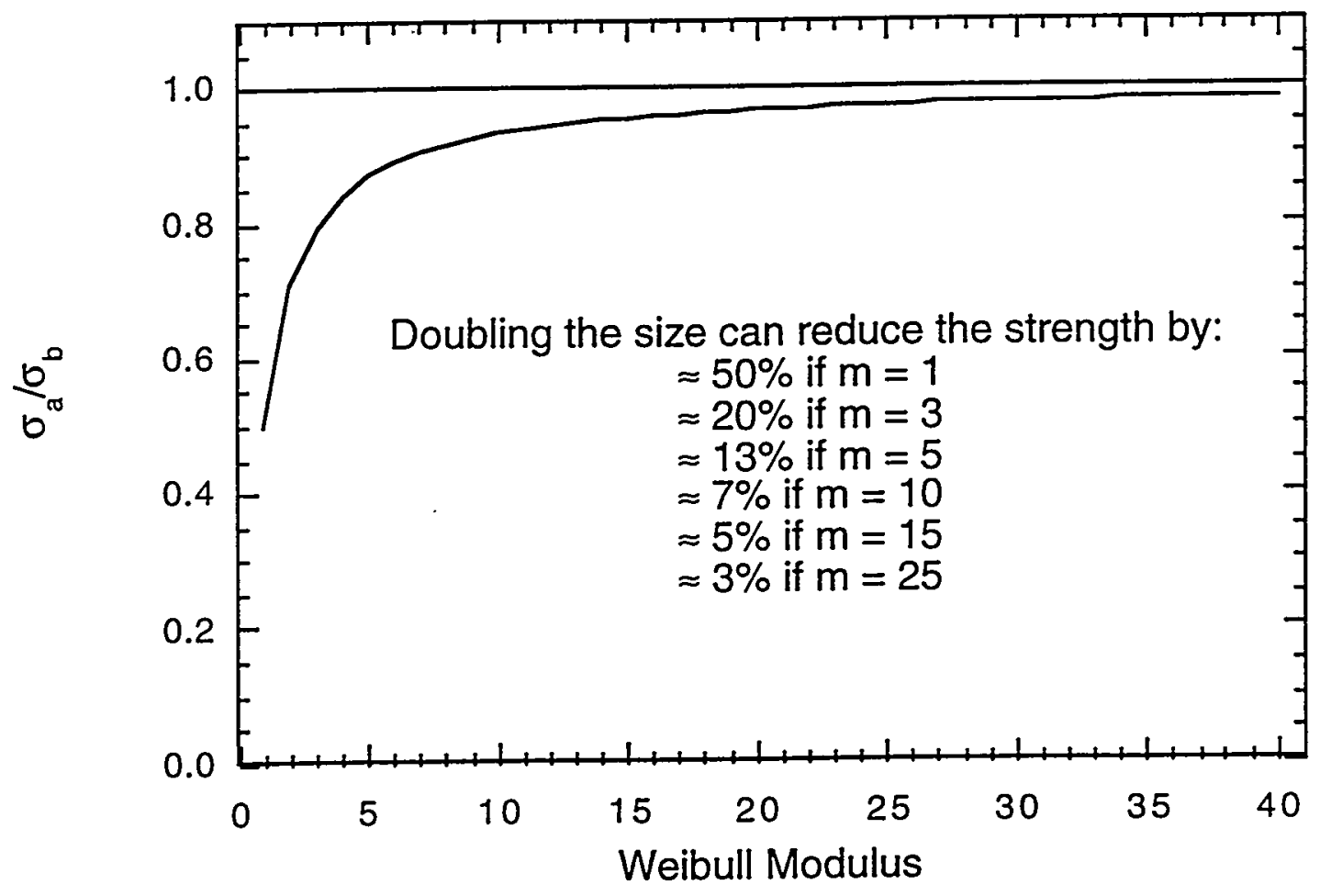

Figure 18. A larger Weibull modulus is also advantageous because strength-size-scaling is not as severe as that for a ceramic with a relatively low Weibull modulus (a). An example of this sizescaling is shown in (b) for the tensile strength of a ceramic material. 


\subsection{Additional Factors Affecting Mechanical Robustness}

\subsubsection{Residual Stress \& Stress Free Temperature}

Residual stress (e.g., that resulting from thermal expansion mismatches of the material constituents in an MLC) in the dielectric ceramics can detrimentally or beneficially affect their mechanical robustness. Residual tension in the ceramic material will superimpose an added stress to that of service with a summed stress that is closer to the ceramic's tensile strength (see Fig. 19). Conversely, a residual compressive stress will lessen the service stress state and decrease the likelihood of mechanical failure. Ideally, one could engineer in residual compressive stresses and increase the MLC's mechanical robustness.

If the "stress free temperature" of the MLC can be lowered, then its mechanical robustness will be improved because residual tensile stresses would be lowered [6]. The stress free temperature is the temperature at which all the material constituents in a system are at zero or equal stress; it is often assumed to be at the sintering temperature. Thermoelastic residual strain at any given temperature is nominally equal to the product of the thermal expansion mismatch of two unlike materials and the temperature differential between that temperature and the stress free temperature or $\varepsilon=\left(\alpha_{1}-\alpha_{2}\right) \Delta \mathrm{T}$. There are two ways to reduce the thermoelastic residual strain; lessen the mismatch of the thermal expansions or lessen the temperature differential. The former is often limited by the choices of available dielectric ceramics and electrode metals, while the latter effect can be lessened by reducing the stress free temperature. Lastly, a reduction in the residual strain can also be attained through the use of a ductile metal whose deformation acts to relieve stress (this in effect reduces the stress free temperature).

The authors are currently exploring means to non-destructively measure residual stresses in the MLC cover layers or margins. Piezospectroscopy (Raman and Fluorescence) is one promising technique under exploration. If residual stress can be measured, then its technique may be used in the iterative and continuing mechanical robustness improvement of MLCs. 


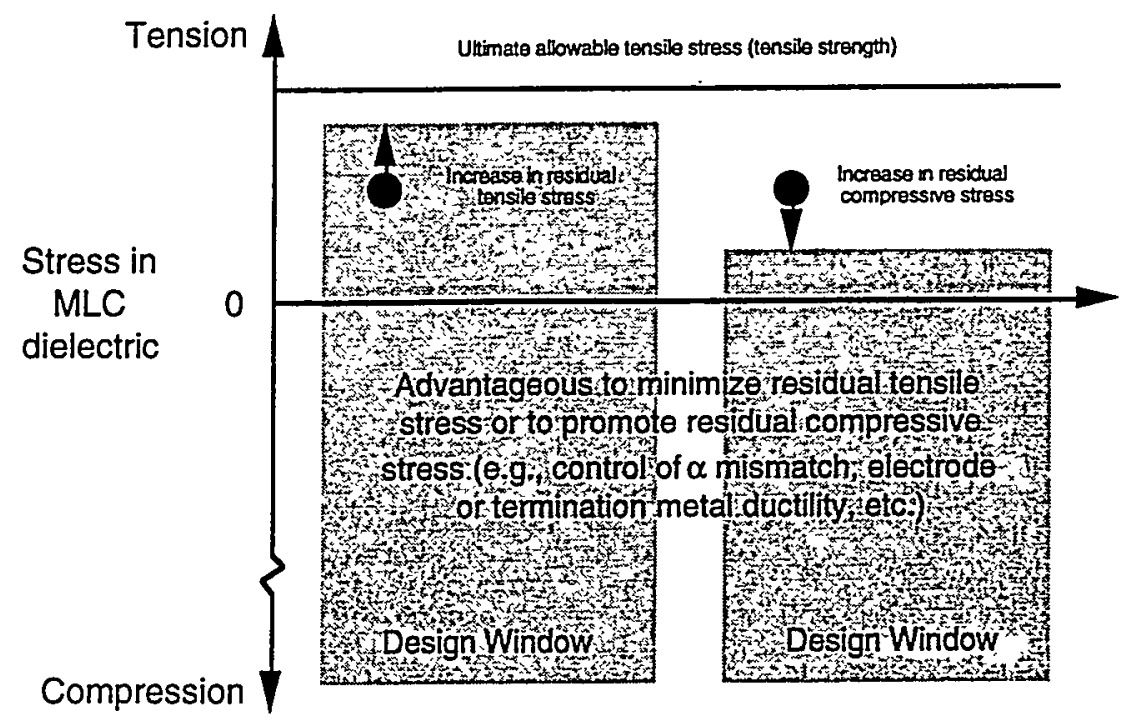

Figure 19. A relatively high tensile residual stress is more detrimental to mechanical robustness.

\subsubsection{Knit Lines and Laminate Adhesion Strength}

An insufficient laminate adhesion strength of tapes in the MLC cover layers can lessen mechanical robustness. A relatively high shear stress can be applied to the bottom cover layer during board flexure, as illustrated in Fig. 11. Ideally, adjoining laminates in the cover layer are well bonded as a result of the sintering process and cumulatively act as a monolithic ceramic dielectric cover layer. However, the interface of the adjoining laminates (knit lines) can consist of a plane that contains a relatively high concentration of pores that weaken or reduce the adhesion strength of the laminates. When the cover layer is subjected to high shear stresses, then the adhesion strength may be exceeded and crack initiation in between laminates or fracture of the cover layer may occur. Consequently, a mechanically robust MLC will have strongly bonded adjoining laminates and minimum porosity in the knit lines.

If knit lines have a relatively high concentration of pores that reduce adhesion strength, then the thickness of the laminates in the cover layer can factor into its mechanical robustness. As shown in Fig. 11, a high shear stress can result in the cover layer during board flexure with the largest stress located at the cover layer's surface. If thin laminates comprise the cover layer in a MLC, then a greater number of knit lines will be located near the cover layer's surface in a region that is subjected to greater shear stresses (as compared to thick laminates comprising the cover layer). An illustration of thin versus thick laminates in a cover layer is shown in Fig. 20. Crack initiation may be more likely in the knit lines during board flexure when thin laminates are weakly bonded 
than if thicker laminates have the same adhesion strength. Consequently, it may be advantageous to use relatively thick laminates in a MLC's cover layer if a monolithic dielectric cannot be attained through complete laminate adhesion.

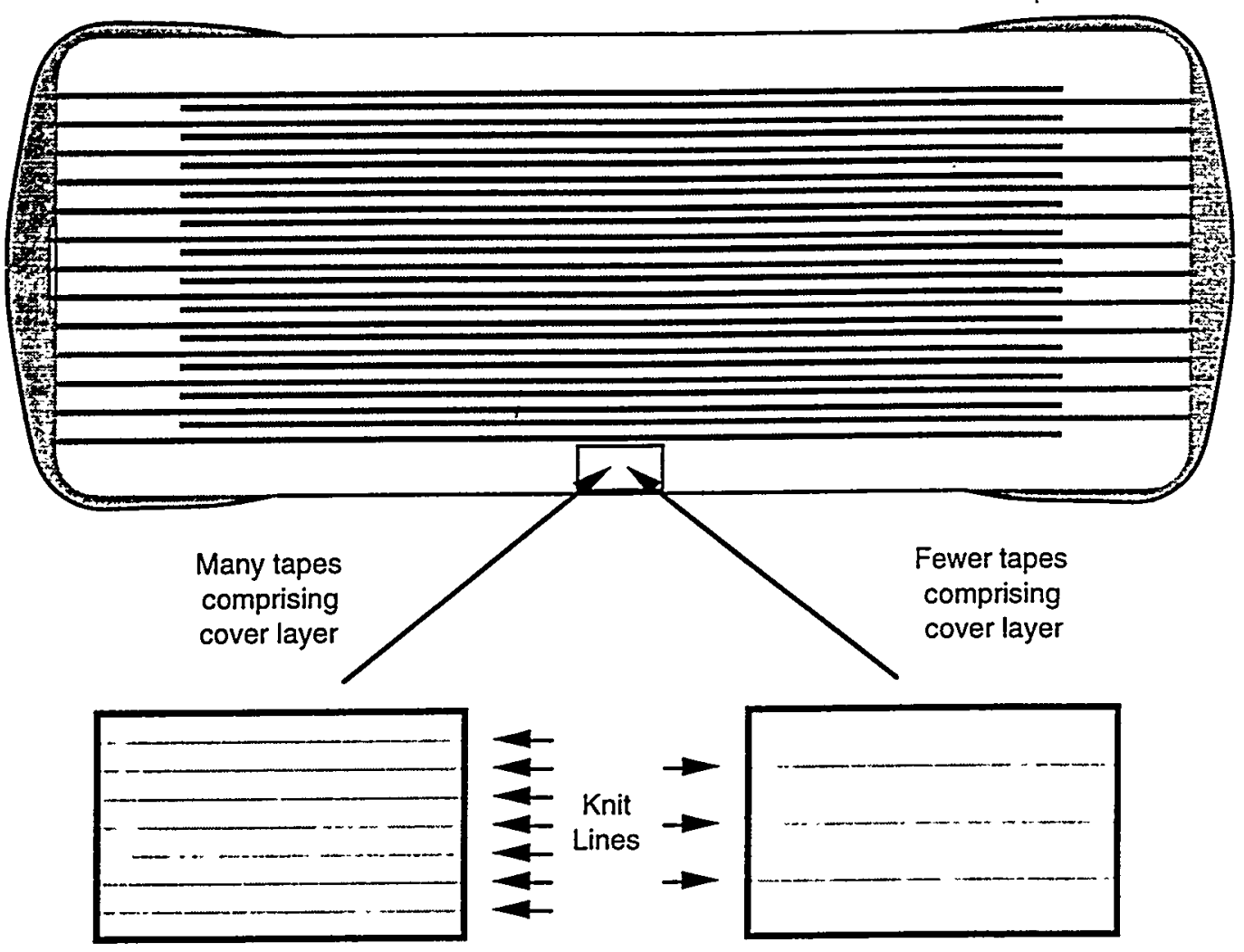

Figure 20. Knit lines can be a source of crack initiation if bonding of adjacent tape laminates is insufficient and the cover layers are subjected to sufficiently high tensile or shear stresses.

\subsubsection{Glass Frit Effects at Termination}

The depth of glass frit penetration into the cover layer where the termination metal ends can affect mechanical robustness of the MLC, especially its mechanical reliability during board flexure. A glass frit interfaces the dielectric ceramic end margins as well as cover layer ends to the termination metal. A schematic illustration of such penetration is shown in Fig. 21. If the frit penetration is relatively deep into the cover layer, then it can act as a relatively large surface-flaw (bottom illustration in Fig. 21) or severe stress concentrator on the surface of the MLC's cover layer during board flexure. The shear loading portrayed in Fig. 11 can apply a sufficient stress to the MLC's surface and the frit penetration can act as a strength-limiter (analogous to a relatively deep 
scratch on flexed glass). The deeper the frit penetration, the larger the effective flaw size becomes. Consequently, maximum mechanical robustness will exist only if such glass frit penetration is minimized. This location is often that of crack initiation when a surface mounted MLC is subjected to a large deflection due to board flexure [19].

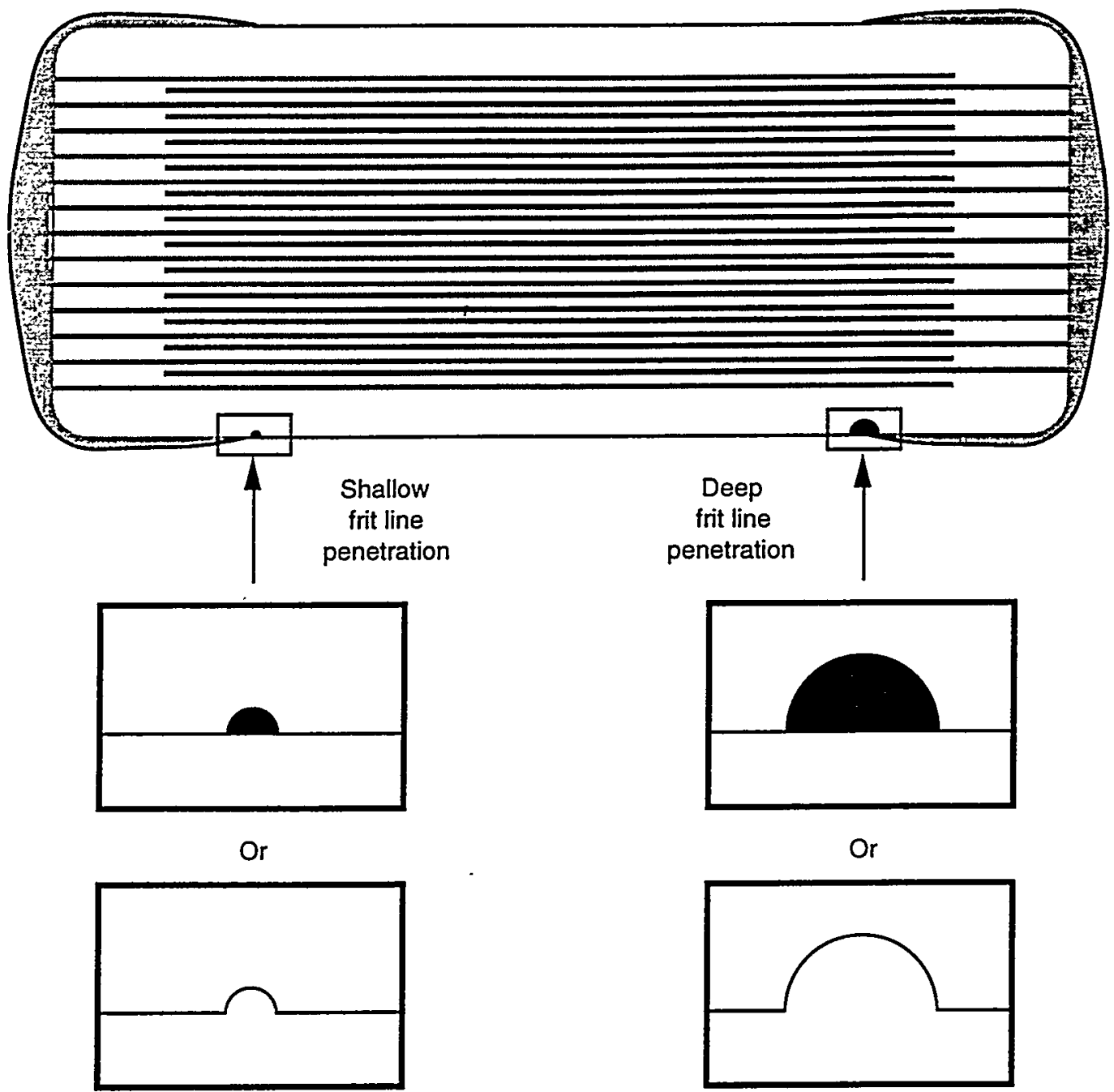

Figure 21. The depth of penetration of the glass frit at the end of the termination metal can affect mechanical robustness. A large depth in the cover layer can be problematic if the MLC's cover layer is subjected to tensile stress (like that for the case during board flexure). 


\subsubsection{Thermal Shock}

The thermoelastic property mismatches between the termination metal and dielectric ceramic can affect thermomechanical robustness during soldering. Such analyses have been performed by Van Den Avyle and Mecholsky [20]. Firstly, thermal expansion mismatch can affect thermal shock susceptibility. The termination metal will likely have a larger-valued coefficient of thermal expansion than the dielectric ceramic. When the MLC is soldered, the termination metal will be quickly heated by the molten solder; the termination metal will consequently try to expand but it will be restrained by the dielectric ceramic (with its lower coefficient of thermal expansion) that it is bonded to. The termination metal will then be subjected to residual compression while the dielectric ceramic beneath it will be subjected to residual tension, as illustrated in Fig. 22.

The magnitudes of the thermal stresses will lessen with time as the dielectric ceramic becomes heated. Consequently, thermal shock susceptibility will be minimized if thermal extremes between the termination metal and dielectric ceramic are minimized. One method to achieve this is through the preheating of the MLC prior to its soldering.

Thermal shock susceptibility is of greater concern for larger-sized MLCs [21]. The reason for this is the lower thermal conductivity of the dielectric ceramic as compared to that for the termination metal. As larger-sized MLCs are being soldered, the dielectric ceramic in contact with the termination metal may not transfer heat quickly enough throughout the dielectric ceramic and a relatively large thermal gradient can be set up through the dielectric ceramic as a consequence. The colder end of the gradient in the dielectric ceramic will then be subjected to a tensile stress due to thermal expansion effects. With time, this gradient in the dielectric ceramic will lessen; however it lessens more rapidly for smaller-sized MLCs than larger-sized ones. Consequently, a relatively large tensile stress can exist in the dielectric ceramic for a longer period of time and thusly increase the likelihood of thermal shock fracture.

The authors wish to provide the following closing commentary on thermal shock testing. Thermal shock testing of ceramics is performed through fast heating or quenching; the proper manner of subjecting the thermal excursion will depend on how the component of interest is thermally shocked. Quenching is a common thermal shock test [4]; however, it may not be the most appropriate method of examining thermal shock susceptibility of MLCs as it tends to exploit surface flaws as strength-limiters. If one could quench the termination metal, then it would subsequently contract while the dielectric ceramic beneath it would simultaneously restrain it. However, the termination metal would be in tension while the dielectric ceramic end margin would 
be compressively loaded. Quenching the whole MLC would only introduce more complicated (and non-representative) thermal shock effects. If the cover layers and margins in a MLC are quenched, then their surfaces will be initially colder than the bulk, and they will be subjected to potentially high tensile stresses that cause fracture. Surface flaws on the cover layers and margins would likely be strength-limiters (and perhaps independent of thermal failures that may result from the soldering process where tensile stresses are located in the interior). This is a situation that the MLCs are not subjected to during their surface mounting and this type of failure may not provide useful data that is representative of the MLC's mechanical robustness.

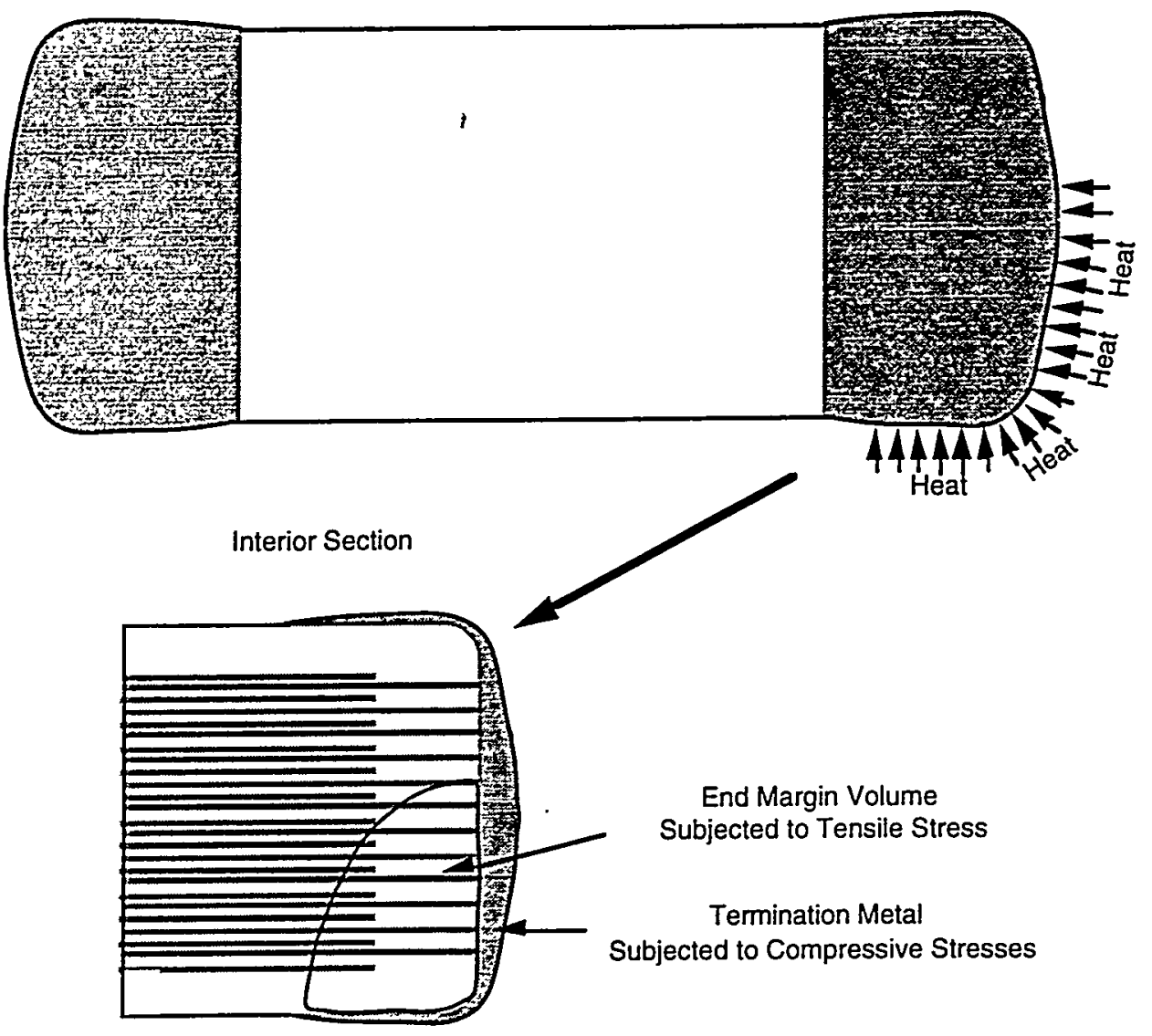

Figure 22. Heating the exterior of a MLC causes the surface to be subjected to compressive stresses while the near-surface-interior is subjected to tensile stresses. This is due to thermal expansion mismatches between the termination metal and the dielectric ceramic. 


\section{SUMMARY}

The present study consisted of two efforts: the measurement of several mechanical properties of dielectric ceramics in MLCs and the consideration of what effects other parameters have on MLC mechanical reliability or "robustness." If MLC mechanical reliability is a limiting factor to long-term electronic function, then it is clearly advantageous to use a MLC with maximum mechanical robustness. The generated results and survey of other factors are described from the perspective of structural ceramic design and interpreted in a manner that a MLC manufacturer or end-user may use to improve MLC mechanical reliability. The trends in the measured properties and other parameters in toto portray the potential MLC mechanical robustness.

The measurement of mechanical properties of the dielectric ceramics in MLCs comprised the majority of this study. The Young's modulus, hardness, fracture toughness, and potential strength distributions (calculated from a measured hypothetical flaw-size distribution) of the dielectric ceramics in three equivalent (X7R 0805 0.1 $\mu \mathrm{F}$ ) MLCs were measured in-situ. The three MLCs were kept anonymous and designated as MLC-A, MLC-B, and MLC-C. From a perspective of a structural ceramic designer, the authors conclude that if the three MLC sets were to be subjected to an equal service stress state that the dielectric ceramic in the MLC-C would mechanically perform the best, followed in turn by the dielectric ceramic in the MLC-A and then that in the MLC-B (all other things being equal). This conclusion is based on the dielectric ceramic in MLC-C having the highest characteristic strength (through the consideration of secondary phase inclusions) and fracture toughness.

Other factors, although not quantified, can also affect mechanical performance and should be considered in the optimization of mechanical robustness. Parameters such as electrode centering, cover layer and margin thicknesses, residual stress, stress-free temperature, adhesion strength of adjoining laminates in MLC cover layers, thickness of laminates comprising the cover layer, glass frit effects, and thermal shock susceptibility can all affect MLC mechanical robustness, and their roles in mechanical reliability were qualitatively presented. To maximize mechanical robustness, it is advantageous to promote the centering of electrodes, maximize cover layer and margin thicknesses, minimize residual tensile stresses and the stress-free temperature, maximize adhesion strength of cover layer laminates (or maximize cover layer thickness if adhesion strength is not maximized), and minimize glass frit penetration at the end of the termination metal. 
The authors believe that appropriate design of a MLC, in which service- or manufacturing-induced tensile stresses are minimized, will have more of an impact on improved MLC mechanical robustness than any improvement in mechanical properties of $\mathrm{BaTiO}_{3}$ ceramics. Barium titanate ceramics were never intended to be structural materials, so drastic improvement in their mechanical properties is unlikely. The fracture toughnesses and strengths of structural ceramics, like those for silicon nitride or partially-stabilized zirconia, have doubled or even tripled over the years as their engineering has matured. However, it is doubtful that the fracture toughness of $\mathrm{BaTiO}_{3}$ will enjoy the same fracture toughness and strength development because there is not an economic driving force to fund that (unlike for silicon nitride and zirconia). Appropriate or improved design to limit service tensile stresses will likely have more of an effect in the improvement of MLC mechanical robustness than tinkering with $\mathrm{BaTiO}_{3}$ to make it twice as tough or strong. Engineering advances have increased the fracture toughness of structural ceramics up to 7-12 $\mathrm{MPa} / \mathrm{m}$; doubling the fracture toughness of $\mathrm{BaTiO}_{3}$ would increase it only to 2.5-3 $\mathrm{MPa} \sqrt{\mathrm{m}}$. Additionally, structural ceramics can have flexure strengths larger than $1000 \mathrm{MPa}$, while the strengths of the strongest $\mathrm{BaTiO}_{3}$ ceramics are an order of magnitude less [1]. Doubling the strength and fracture toughness of $\mathrm{BaTiO}_{3}$ ceramics would be helpful; however, designing MLCs so that imposed tensile stresses are halved would result in the same mechanical robustness state, and would be much less of an engineering endeavor. 


\section{REFERENCES}

[1] S. W. Freiman and R. C. Pohanka, "Review of Mechanically Related Failures of Ceramic Capacitors and Capacitor Materials," Journal of the American Ceramic Society, 72 2258-63 (1989).

[2] W. C. Oliver and G. M. Pharr, "An Improved Technique for Determining Hardness and Elastic Modulus Using Load and Displacement Sensing Indentation Experiments," Joumal of Materials Research, 7 1564-83 (1992).

[3] G. R. Anstis, P. Chantikul, B. R. Lawn, and D. B. Marshall, "A Critical Evaluation of Indentation Techniques for Measuring Fracture Toughness: I, Direct Crack Measurements," Journal of the American Ceramic Society, 64 533-538 (1981).

[4] C. R. Koripella, "Mechanical Behavior of Ceramic Capacitors," presented at the $41^{\text {st }}$ Electronic Components and Technology Conference (ECTC), May 13-15, 1991.

[5] J. M. Blamey and T. V. Parry, "Strength and Toughness of Barium Titanate Ceramics," Journal of Materials Science, 28 4988-4993 (1993).

[6] A. A. Wereszczak, K. Breder, M. K. Ferber, R. J. Bridge, L. Riester, and T. P. Kirkland, "Failure Probability Prediction of Dielectric Ceramics in Multilayer Capacitors," Multilayer Electronic Ceramic Devices, Ceramic Transactions, Vol. 97, pp. 73-83, 1999.

[7] A. A. Wereszczak, T. P. Kirkland, K. Breder, H. -T. Lin, and M. J. Andrews, "Biaxial Strength, Strength-Size-Scaling, and Fatigue Resistance of Alumina and Aluminum Nitride Substrates," In review, International Journal of Microcircuits and Electronic Packaging, 1999.

[8] Y. Zhang, N. Uchida, K. Uematsu, T. Hotta, K. Nakahira, and M. Naito, "A Direct Examination of the Fracture Strength-Defect Size Relationship in Alumina Ceramics," Key Engineering Materials, 159-160 269-274 (1999).

[9] N. Orlovskaja, H. Peterlik, W. Steinkellner, K. Kromp, "Prediction of Strength of Recrystallized Siliconcarbide from Pore Size Measurement, Parts I and II," In review, Journal of Materials Science, 1999.

[10] "Standard Practice for Fractography and Characterization of Fracture Origins in Advanced Ceramics," ASTM C1233-96a, Annual Book of ASTM Standards, Vol. 15.01, American Society for Testing and Materials, West Conshohocken, PA, 1998.

[11] "Life Prediction Methodology for Ceramic Components of Advanced Heat Engines, Phase 1," Prepared by AlliedSignal Engines, Phoenix, AZ, ORNL/Sub/89-SC674/1-2, DOE Office of Transportation Technologies, 1995.

[12] "AVX SMPS Caps/High Voltage Caps, Tip \& Ring/Cap Arrays/Discoidals, Advanced Applications," Report S-ADVCAP10M699-C, AVX, 1999. 
[13] M. H. Megherhi, G. O. Dayton, T. R. Shrout, and J. J. Mecholsky, Jr., "Indentation Fracture of Lead Magnesium Niobate-Based Multilayer Composite Structures," Joumal of Materials Research, 5 515-523 (1990).

[14] E. R. Fuller, B. R. Lawn, and R. F. Cook, "Theory of Fatigue for Brittle Flaws Originating from Residual Stress Concentrations," Journal of the American Ceramic Society, 66 314-321 (1983).

[15] R. F. Cook, S. W. Freiman, B. R. Lawn, and R. C. Pohanka, "Fracture of Ferroelectric Ceramics," Ferroelectrics, 50 267-272 (1983).

[16] A. A. Wereszczak, T. P. Kirkland, M. K. Ferber, and M. J. Andrews, "Prediction of SiAlON Diesel Valve Failure Probability Using AlliedSignal's CERAMIC and ERICA Life Prediction Codes," Ceramic Engineering and Science Proceedings, Vol. 18, pp. 475-484, 1997.

[17] M. J. Andrews, A. A. Wereszczak, and K. Breder, "Prediction of the Inert Strength Distribution of $\mathrm{Si}_{3} \mathrm{~N}_{4}$ Diesel Valves" In press, Ceramic Engineering and Science Proceedings, Vol. 20, 1999.

[18] "Chip Type Monolithic Ceramic Capacitor, Bending Strength Technical Data," Report TD.No.C05E, Murata Manufacturing Co., Ltd., 1997.

[19] J. Bergenthal, "Mechanical Strength Properties of Multilayer Ceramic Chip Capacitors," presented at the $11^{\text {th }}$ Capacitor and Resistor Technology Symposium (CARTS), March 4-7, 1991.

[20] J. A. Van Den Avyle and J. J. Mecholsky, "Analysis of Soldering-Induced Cracking of $\mathrm{BaTiO}_{3}$ Ceramic Capacitors," Ferroelectrics, 50 293-298 (1983).

[21] J. Prymak, "Ceramic Capacitors," PCIM, September, 76-80 (1997).

\section{ACKNOWLEDGMENTS}

The authors wish to thank P. Crosby of Visteon for supplying the MLCs for this study. Gratitude is expressed for the insights and suggestions provided by L. Mann of KEMET and J. Canner of Murata. The authors also wish to thank ORNL's H. -T. Lin, R. Ott, and A. Pasto for their review of this report and for their helpful comments. Lastly, DOE's P. Davis and D. Hamilton, and ORNL's D. Stinton are thanked for their continued financial support of this project. 
D. Adams

9102-1, MS-8038

P. Becher

4515, MS-6068

E. Bloom

4500S, MS-6132

R. Bradley

4500S, MS-6161

K. Breder (4)

4515, MS-6069

R. Johnson

4515, MS-6066

T. Kirkland

4515, MS-6069

H. -T. Lin

4515, MS-6068

A. Pasto

4515, MS-6062
F. Peng

9102-1, MS-8038

M. Rawlins

4500N, MS-6269

L. Riester (4)

4515, MS-6069

J. Roberto

$4500 \mathrm{~N}, \mathrm{MS}-6240$

D. Stinton

4515, MS-6063

A. Schaffhauser 4500 N, MS-6186

A. Wereszczak (40)

4515, MS-6069

Central Research Library

Laboratory Records, ORNL-RC (3) 
T. Barbee, Jr.

Lawrence Livermore National Lab.

Materials Science \& Tech. Div.

P. O. Box $808, \mathrm{~B} 235, \mathrm{R} 1007$

Mailcode L-350

Livermore, CA 94551

J. Beatty

Army Research Laboratory

Weapons Materials Division

AMSRL-WM-MC

Aberdeen Proving Ground, MD 21005

\section{J. Bergenthal}

KEMET Electronics Corporation

PO Box 5928

Greenville, SC 29606

S. Binapal

Gennum Corporation

PO Box 489, Station A

Burlington, Ontario

Canada L7R 3Y3

R. Bridge (4)

131 Bridge St.

Stamford, Ct. 06905

C. Bourne

Murata Electronics North America, Inc.

1900 West College Ave.

State College, PA 16801-2799
G. Campisi

Office of Navel Research

Code 334

800 N. Quincy St.

Arlington, VA 22214-5660

\section{J. Canner}

Murata Electronics North America, Inc. 1900 West College Ave.

State College, PA 16801-2799

M. Cole

Army Research Laboratory

Weapons Materials Division

AMSRL-WM-MC

Aberdeen Proving Ground, MD 21005

G. Crosbie

Ford Research Laboratory

20000 Rotunda Dr.

MD 3182, SRL, PO Box 2053

Dearborn, MI 48121-2053

P. Crosby

Visteon Automotive Systems

ETC 17000 Rotunda Dr. C-180

Dearborn, MI 48121-6010

\section{S. Cygan}

Olean Advanced Products

PO Box 493

Olean, NY 14760 
P. Davis

U.S. Department of Energy

1000 Independence Ave.

Forrestal Bldg., EE-32

MS 6A-116, RM 5G-023

Washington, DC 20585

G. Dayton

Vitramon Inc.

PO Box 544

Bridgeport, CT 06601

R. Diaz

DaimlerChrysler Corporation

30900 Stephenson

Madison Heights, MI 48071

D. Dimos

Sandia National Laboratory

MS 1411

PO Box 5800

Albuquerque, NM 87185-1411

J. Dougherty

Pennsylvania:State University

144 Materials Research Laboratory

University Park, PA 16802

C. Dow

USCAR

1000 Town Center Building

Suite 300

Southfield, MI 48075

R. Fagan

Carborundum Microelectronics

2050 Cory Rd.

Sanborn, NY 14132
S. Freiman

NIST

100 Bureau Dr., MS-8520

Gaithersburg, MD 20899-8520

D. Freitag

Bayside Materials Technology

21150 New Hampshire Ave.

Brookeville, MD 20833

A. Gale

Ford Motor Company

P.O. Box 2053

MD-1170, SRL

Dearborn, Mi 48121-2053

D. Hamilton

U.S. Department of Energy

1000 Independence Ave.

Forrestal Bldg., EE-32

MS 6A-116, RM 5G-046

Washington, DC 20585

J. Helfinstine

Corning Incorporated

Science \& Technology

SP-FR-04-1

Corning, NY 14831

J. Hill

Olean Advanced Products

PO Box 493

Olean, NY 14760

W. Huebner

University of Missouri-Rolla

Dept. of Ceramic Engineering

222 McNutt Hall

Rolla, MO 65409-0810 
R. Koripella

Motorola - CTC

Maildrop: AZ83/FPD28

7700 S. River Park Way

Tempe, AZ 85284

R. Kost

U.S. Department of Energy

1000 Independence Ave.

Forrestal Bldg., EE-32

MS 6A-116, RM 5G-045

Washington, DC 20585

M. Lanagan

Pennsylvania State University

258 Materials Research Laboratory

University Park, PA 16802

R. Malcolm

DaimlerChrysler Corporation

Liberty \& Technical Affairs, Bldg 2A

30900 Stephenson Highway

Madison Heights, MI 48071

L. Mann

KEMET Electronics Corporation

PO Box 849

201 Fairview St. Ext.

Ft. Inn, SC 29644-0849

P. McCluskey

CALCE EPRC

University of Maryland

College Park, MD 20742
J. McLarney

Olean Advanced Products

PO Box 493

Olean, NY 14760

Kevin McNerney

Coors Ceramics Company

600 Ninth Street

Golden, CO 80401

J. Mecholsky, Jr.

University of Florida

227-A Rhines Hall

Gainsville, FL 32611

M. Megherhi

TAM Ceramics Inc.

4511 Hyde Park Blvd.

PO Box 67

Niagara Falls, NY 14305-0067

J. Merritt

U.S. Department of Energy

1000 Independence Ave.

Forrestal Bldg., EE-32

MS 6A-116, RM 5G-064

Washington, DC 20585

R. Mistler

Richard E. Mistler, Inc.

PO Box 296

1430 Bristol Pike

Morrisville, PA 19067

L. Mosiman

MTS Systems Corporation 14000 Technology Dr.

Eden Prairie, MN 55344-2290 
B. Murty

General Motors Corporation

GM R\&D Center

MC: 480-106-A26

30500 Mound Rd.

Warren, MI 48090-9055

M. Natishan

Mechanical Engineering Department

University of Maryland

College Park, MD 20742-3035

D. Nordstorm

DaimlerChrysler Corporation

800 Chrysler Dr.

CIMS 484-02-15

Auburn Hills, MI 48326-2757

R. Pohanka

U.S. Department of the Navy

Office of Naval Research ONR 332

800 N. Quincy St.

Arlington, VA 22217

J. Prymak

KEMET Electronics Corporation

PO Box 5928

Greenville, SC 29606

C. Randall

Pennsylvania State University

151 Materials Research Laboratory

University Park, PA 16802
S. Rogers

U.S. Department of Energy 1000 Independence Ave.

Forrestal Bldg., EE-32

MS 6A-116, RM 5G-046

Washington, DC $20585^{\circ}$

R. Sands

20504 Riggs Hill Way

Brookeville, MD 20833

David Sanislow

General Motors Corporation

30500 Mound Rd.

MC: 480-106-244 REB

Warren, MI 48090

R. Satula

U.S. Department of Energy

1000 Independence Ave.

Forrestal Bldg., EE-32

MS 6A-116, RM 5G-046

Washington, DC 20585

T. Shrout

Pennsylvania State University

150 Materials Research Laboratory

University Park, PA 16802

G. Smith

General Motors Corporation

Advanced Technology Vehicles

Loc. TO BIdg. 237, MS 1437

3050 Lomita Blvd.

PO Box 2923

Torrance, CA 90509-2923 
R. Tummala

Georgia Institute of Technology

Materials Science \& Engineering

778 Atlantic Dr.

Atlanta, GA 30332-0245

B. Tuttle

Sandia National Laboratory

MS 1405

PO Box 5800

Albuquerque, NM 87185-1405

K. Uchino

Pennsylvania State University

134 Materials Research Laboratory

University Park, PA 16802-4800

O. Viergutz

DaimlerChrysler Corporation

800 Chrysler Dr.

CIMS 483-01-07

Auburn Hills, MI 48326-2757

E. Vogel

Lucent Technologies

600 Mountain Ave.

Room 1A-142

Murray Hill, NJ 07974-0636
J. Wimmer

AlliedSignal Ceramic Components

Bldg. $1 / 5$

2525 West 190th St.

Torrance, CA 90504

D. Wilcox

Motorola - CTC

Maildrop: AZ83/FPD28

7700 S. River Park Way

Tempe, AZ 85284

D. Young

Motorola

4000 Commercial Ave.

Northbrook, IL 60062-1840

A. White

DaimlerChrysler Corporation

800 Chrysler Dr.

CIMS 483-01-07

Auburn Hills, MI 48326-2757 